\title{
Division I College Student-Athlete Career Situation and Attitudes toward Career Counseling
}

Adrian J. Ferrera

Follow this and additional works at: https://researchrepository.wvu.edu/etd

\section{Recommended Citation}

Ferrera, Adrian J., "Division I College Student-Athlete Career Situation and Attitudes toward Career Counseling" (2014). Graduate Theses, Dissertations, and Problem Reports. 5591.

https://researchrepository.wvu.edu/etd/5591

This Dissertation is protected by copyright and/or related rights. It has been brought to you by the The Research Repository @ WVU with permission from the rights-holder(s). You are free to use this Dissertation in any way that is permitted by the copyright and related rights legislation that applies to your use. For other uses you must obtain permission from the rights-holder(s) directly, unless additional rights are indicated by a Creative Commons license in the record and/ or on the work itself. This Dissertation has been accepted for inclusion in WVU Graduate Theses, Dissertations, and Problem Reports collection by an authorized administrator of The Research Repository @ WVU.

For more information, please contact researchrepository@mail.wvu.edu. 
Division I College Student-Athlete Career Situation and Attitudes toward Career Counseling

Adrian J. Ferrera, EdM

Dissertation submitted to the
College of Physical Activity and Sport Science
at West Virginia University
in partial fulfillment of the requirements
for the degree of

Doctor of Philosophy

in

Sport and Exercise Psychology

Jack Watson, Ph.D., Chair

Edward Etzel, Ed.D.

Sam Zizzi, Ed.D.

Ed Jacobs, Ph.D.

Damien Clement, Ph.D.

College of Physical Activity and Sport Sciences

Department of Sport Sciences

Morgantown, West Virginia

2014

Keywords: Student-Athlete, Career Situation, Career Counseling, Attitudes Copyright 2014 Adrian Ferrera 


\section{Abstract \\ Division I College Student-Athlete Career Situation and Attitudes toward Career Counseling}

\section{Adrian J. Ferrera}

Few student-athletes advance to the professional level following their collegiate athletic career, leaving many to pursue alternative career paths. Although much attention has been dedicated to student-athlete academic progress and graduation rates, little attention has been given to studentathlete career development and their attitudes toward career counseling. Since the career development of student-athletes is complex and is affected by several variables, the purposes of the present study were threefold: 1) determine the career situation of male and female studentathletes attending an NCAA Division I university, 2) determine if differences existed between student-athletes and non-athlete students in their attitudes toward career counseling, and 3) determine which demographic variables, career situation factors, and personality factors had the most influence on student-athlete attitudes toward career counseling. Of the student-athletes surveyed $($ male $=189$, female $=164)$, only 13 met the criteria of being career savvy. The results also indicated that student-athletes value career counseling more than non-athlete students and that females value career counseling more than males. However, males expressed a higher degree of stigma toward career counseling than females. Hierarchical regression analyses revealed that the variables sport facilitates, scholarship status, and barriers were predictors of male value toward career counseling, and the variables lack of career interest and use of services were predictors of male stigma toward career counseling. Hierarchical regression analyses revealed that the variable sports facilitates was the only significant predictor of female value toward career counseling, and the variables career locus of control, sport identity and sport facilitates were significant predictors of female stigma toward counseling. 


\section{Acknowledgements}

First, I would like to thank my wife, Pascha Adamo, for enduring this process with me from beginning to end. It has always been a joy to see your smiling face after longs days and nights. Your patience, love, and kindness have been a great balance for me. I am blessed to have you as part of my support system and I look forward to the next chapters our lives together.

To my mother, father, and brothers, I would like to thank you for your continuous prayers, support, and understanding during this process. Hearing "How is your dissertation coming?" or "Are you a Doctor yet?" in every phone call was a reminder that you all wanted this for me just as bad as I wanted it for myself.

I would like to express my sincere appreciation to my chair and advisor Dr. Jack Watson who has been instrumental in the completion of this dissertation and my time at WVU. With your many commitments, I have always felt that you have made time for me. Thank you for believing in me and for never giving up on me.

To Dr. Sam Zizzi, I cannot thank you enough for guiding me through the world of statistics and for finding a way to keep me motivated via Twitter. Please keep \#ResearchMountain trending!

Dr. Edward Etzel, I thank you for your wisdom and for providing me with every possible article, book, handout, and resource regarding student-athlete development.

I would also like to thank Dr. Damien Clement for always pushing me to continue with my research. I am not sure how I would have survived this program without your guidance.

To all of the student-athletes, coaches, and administrators, you were all instrumental in the data collection process and this dissertation would not have been completed without you.

I would also like to thank Dr. Ed Jacobs for his willingness to serve on my committee.

To my colleagues at WVU's Career Services Center, I thank you for their continuous words of encouragement. 
Table of Contents

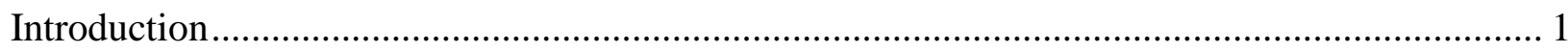

Statement and Significance of the Problem................................................................. 6

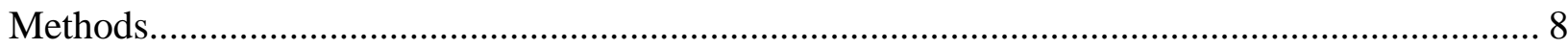

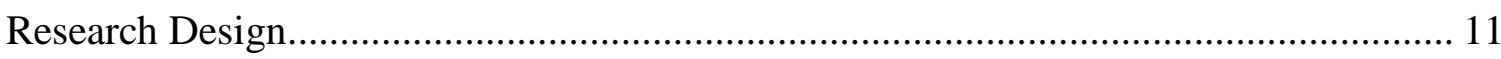

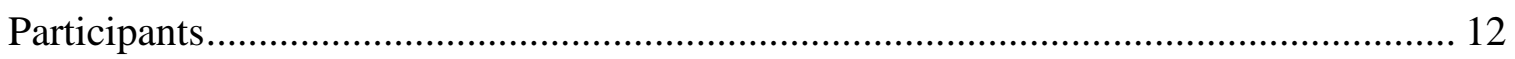

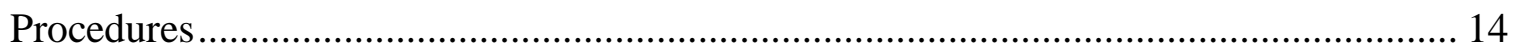

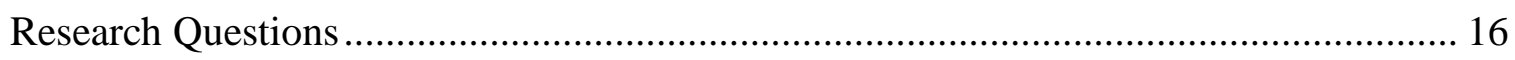

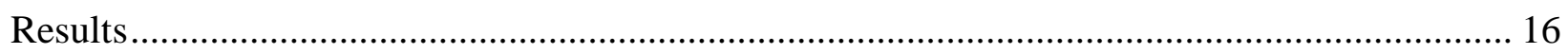

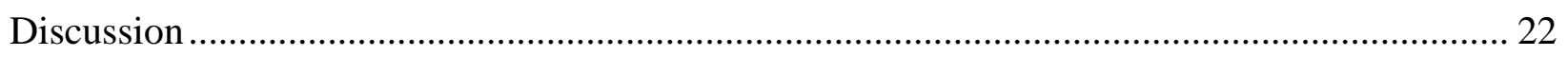

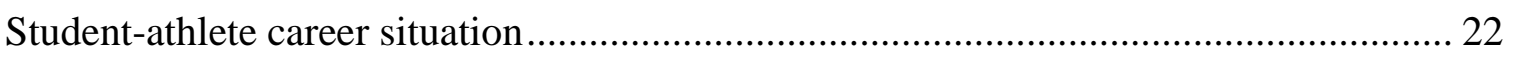

Attitudes toward career counseling....................................................................... 25

Practical implications ........................................................................................ 30

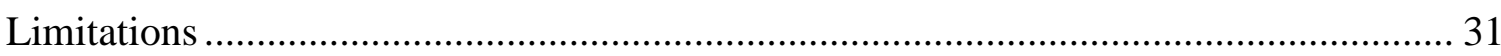

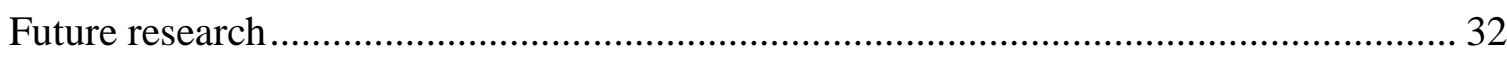

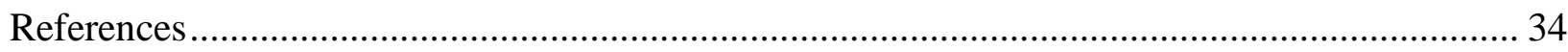

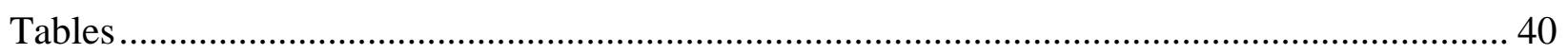

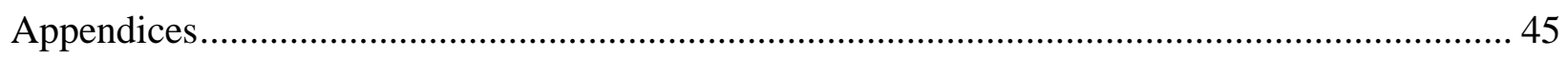

Appendix A - Participant cover letter ……………….......................................... 45

Appendix B - Student-athlete demographic questionnaire ………………………......... 46

Appendix C - Student-Athlete Career Situation Inventory - Revised Male (SACSI-RM)

Appendix D - Student-Athlete Career Situation Inventory - Revised Female (SACSI-FM)

Appendix E-Attitudes Toward Career Counseling Scale (ATCCS) ...... 5

Appendix E - Attitudes Toward Career Counseling Scale (ATCCS) ............................... 54

Appendix F - Student Demographic Questionnaire ………………….......................... 56

Appendix G - Athletic Identity Measurement Scale (AIMS) ……………………........ 58

Appendix H - Career Locus of Control Scale (CLCS) ………………………................. 59

Appendix I - Extended Review of Literature ………………...................................... 60 


\section{Introduction}

\section{Division I College Student-Athlete Career Situation and Attitudes toward Career Counseling}

Over the past two decades, researchers have conducted a great deal of research with the goal of understanding college student-athletes' academic progress and graduation rates (Paskus, 2012; Petr \& Paskus, 2009). At the Division I level, researchers have found that student-athletes have consistently graduated at higher rates than non-athlete college students since 1986 (Petr \& McArdle., 2012). Student-athlete graduation rates have also steadily increased since this type of data collection started in 1984. At present, $65 \%$ of student-athletes graduate from college (Petr et al., 2012). Even though several studies have indicated that many student-athletes believe they will play professionally (e.g. Brown, Glastetter-Fenders \& Shelton, 2000; Parker, 1994;

Smallman \& Sowa, 1996), very few student-athletes (i.e. approximately $3 \%$ ) move on to the professional ranks following college (NCAA, 2012a). So what happens to these other studentathletes following graduation? Are these student-athletes prepared for their careers after college?

Much attention has been given to student-athlete graduation rates, with much less attention given to student-athlete career development. Even though student-athletes are graduating at higher rates, this does not mean that they are prepared to pursue a career after graduation. In 1987, Kennedy and Dimick suggested that more attention be given to studentathlete career development since student-athletes often scored lower on career development measures when compared to non student-athletes. For more than 30 years, researchers have claimed that student-athletes have been enrolled in specific majors because the courses and professors in those majors were student-athlete friendly, making it easy for student-athletes to meet NCAA eligibility requirements (Adler \& Adler, 1980; Beamon, 2008; Underwood, 1980). These practices are exactly what the Knight Commission (2001) believed would happen when 
the NCAA instituted several reforms and criteria for student-athlete eligibility. While studentathletes in these programs may receive a degree, the quality and applicability of the degree can sometimes be called into question and may leave the student-athlete in an unfortunate situation following graduation when they find it very difficult to find employment.

Although declaring a major may provide some direction or focus for students and student-athletes alike, simply taking courses in a particular field does not prepare them for a career. Students should also explore their options through internships, attending career fairs, visiting their on-campus career center, and engaging in socially enriching activities (Carodine, Almond \& Gratto, 2001; Cox, Sadberry, McGuire \& McBride, 2009). Career counseling can be utilized to assist with self-exploration, career decision-making, and gaining occupational information (Brown, 2003). Unfortunately, Fouad, Guillen, Harris-Hodges, Henry, Novakovic, and Kanatamneni (2006) found that individual career counseling was a service that was underutilized by the student population.

It has been argued that career preparation should begin prior to entering college (Super, 1957b), but some student-athletes attend college for reasons unrelated to academics, and may not follow the same trajectory as non-athletes with regard to their career development. Within a sample of 126 first year Division I student-athletes, Letawsky, Schneider, Pedersen and Palmer (2003) found that the degree programs that were offered, the head coach of the athletic team, the availability of academic support services, the community surrounding the campus, and the school's sports traditions were the top five factors considered when student-athletes selected a college. Data collected from the NCAA GOALS study indicated that more than $80 \%$ of studentathletes across all divisions (i.e. I, II, and III) selected their university based on the possibility of athletic participation (Paskus, 2012). However, it should be noted that more than $90 \%$ of 
Division I student-athletes indicated that graduation from college was important to them. At the same time, some student-athletes are admitted to universities only because of their athletic ability, and attending college is seen as the best way for athletes to develop and showcase their athletic abilities before pursuing a professional athletic career (Adler et al., 1985). While student-athletes could attend college for both academic and athletic reasons, their non-athlete peers select colleges for different reasons (Bui, 2002). This gives non-athlete students the opportunity to focus more exclusively on academic issues, which can lead to their career development.

Regardless of the reasons for attending college, once student-athletes step on campus they should receive proper guidance to assist them with their career development. Understanding the severity of the problems facing student-athletes, universities have taken action to address the needs of this unique group. Several researchers have discussed the implementation of programs and college courses designed to assist student-athletes with their life and career preparation (Jordan \& Denson, 1990; Lenz \& Shy, 2003, Naylor, 1983; Stankovich, Meeker, \& Henderson, 2001; Wooten \& Hinkle, 1994). While some have reported the success of these programs (Meeker \& Stankovich, 1999; Wittmer, Bostic, Phillips, \& Waters, 1981), other researchers have concluded that student-athletes are not as prepared for non-athletic careers as their non-athlete student counterparts (Linnemeyer \& Brown, 2010; Martens \& Cox, 2000).

There are several reasons that could explain this lack of career readiness among studentathletes. Unlike the general student body, student-athletes deal with public scrutiny, have huge time commitments, and take part in physically demanding practices in addition to fulfilling their student responsibilities (Carodine et al., 2001). Self-report data has indicated that Division I student-athletes dedicate 32 to 43 hours per week to their sport and between 31 to 40 hours per 
week to academics while in season (NCAA, 2011). Reports have revealed that football players dedicated the most time ( 81 hours per week) to both athletics and academics, while men's and women's basketball (76.5 hours per week) were close behind (NCAA, 2011).

While time commitment is certainly a big issue affecting college student-athletes, Underwood (1980) believes that there are bigger problems associated with college sports that affect student-athletes. He reported that student-athletes are exploited for their athletic abilities, are granted admission to universities with subpar high school academic records, and may struggle to develop autonomy since they have been "taken care of" since their youth. Most recently, Beamon (2008) reported that some student-athletes have their majors and courses selected for them so they can remain eligible and not necessarily for the betterment of their futures. These athletic related time commitments along with having ones academic decisions taken care of by individuals in a system that may not always be looking out for the studentathlete's best long-term interests can undermine their career development, and negatively influence their ability to prepare for and be successful in a future career

Since career development is a life-long process that involves the interaction of certain behaviors, vocational tasks, decision making, overcoming opposition, attitudes and competencies, the term career maturity has been used to classify one's degree of development (Super, 1957b; Crites, 1961; Hansen, 1974). Although student-athletes have higher graduation rates when compared to non-athlete students (Petr et al., 2012), student-athletes have been found to have lower levels of career maturity (Linnemeyer \& Brown, 2010; Martens \& Cox, 2000). Furthermore, student-athletes have scored in the $27^{\text {th }}$ and $34^{\text {th }}$ percentile on the Career Maturity Inventory (CMI) (Kennedy et al., 1987, Murphy, Petitpas, \& Brewer, 1996), and have also scored in the $25^{\text {th }}$ percentile on the Career Development Inventory (Smallman \& Sowa, 1996). 
As student-athletes function as both students and athletes, researchers have found that certain variables (e.g. athletic identity, career locus of control, and career self-efficacy) influence their career maturity (Kornspan \& Etzel, 2001; Murphy, Petitpas, Brewer, 1996). Super (1957b) believed that completing specific career-related tasks at different periods of life helps to increase one's level of career maturity. Having the belief in one's ability to complete these career-related tasks is defined as career decision self-efficacy (Taylor \& Betz, 1983). Brown and colleagues (2000) concluded that athletes who dedicated more hours to their sport had less career decision self-efficacy. If student-athletes give more time to athletics this decreases their available time for completing career-related tasks. These student-athletes may also give more time to their sport because they may want to become professional athletes or may believe that being an athlete is who they are which leads to them practicing more.

Student-athletes who identify more with their athlete role are said to have a higher athletic identity (Brewer, Petitpas, \& Van Raalte, 1993). Murphy, Petitpas, and Brewer (1996) found that student-athletes with higher athletic identities displayed less career maturity and that student-athletes in revenue producing sports had higher athletic identities than student-athletes in non-revenue producing sports. While some student-athletes may wrestle with their identities, others may have foreclosed on an identity. Those with foreclosed identities commit to a career path without much knowledge or exploration (Marcia, 1966; Medalie, 1981). Most recently, Linnemeyer and Brown (2012) found that student-athletes were more foreclosed than general students and fine arts students. It has also been shown that having a foreclosed identity leads to decreased career maturity (Murphy et al., 1996) and decreased career decision self-efficacy in student-athletes (Brown, Glastetter-Fender, \& Shelton, 2000). 
While Kornspan and Etzel (2001) did not find a link between athletic identity and career maturity, career decision self-efficacy and career locus of control did have an influence on junior college student-athlete career maturity. Student-athletes who expressed high levels of career decision self-efficacy had higher levels of career maturity, and those with an external locus of control had lower levels of career maturity. Student-athletes with an external locus of control believe their actions have no impact on their future career attainment. As referenced earlier, student-athletes may not believe they have any control over their future decisions since many aspects of their lives are planned by others (Beamon, 2008; Parker, 1994).

\section{Statement and Significance of the Problem.}

It is understood that student-athletes may only be in college for athletics (Adler et al., 1989; Etzel et al., 2007), may not be prepared for college upon entrance (Purdy, Eitzen \& Hufnagel, 1982; Underwood, 1980), and will have demanding athletic time commitments (NCAA, 2011). However, these reasons should not serve as excuses for their lack of preparation for life or a career following college. Since student-athletes are students, they should receive guidance including career counseling, to enhance their career development during their college years. Most recently, attention has been given to student-athlete graduation rates (Petr et al., 2012, Petr et al., 2009), but there is no recent data that has been gathered on the career readiness of student-athletes. Although, student-athletes may receive some career assistance from their universities and athletic departments (Coleman \& Barker, 1991; Lenz \& Shy, 2003; Naylor, 1983; Stankovich, Meeker, Henderson, 2001; Wooten \& Hinkle, 1994), they have been found to have lower levels of career maturity than non-athlete students (Linnemeyer \& Brown, 2010; Martens \& Cox, 2000). Additionally, student-athletes who dedicate more hours to their sport or who have foreclosed identities, have been shown to display less career decision self-efficacy 
(Brown et al., 2000). Having low levels of career decision self-efficacy is also linked to having low levels of career maturity (Kornspan et al., 2001). It has also been found that student-athletes with higher athletic identities, foreclosed identities, and an external locus of control display less career maturity (Kornspan et al., 2001; Murphy et al., 1996). Based on previous research it is evident that the career development of student-athletes is complex and is affected by several variables.

Previous literature has investigated these variables that are associated with student-athlete career maturity. These studies have used multiple instruments to make conclusions regarding the career development for subgroups of student-athletes (e.g. Brown et al., 2000; Kornspan et al. 2001; Murphy et al., 1996). However, these inventories were not designed with student-athletes in mind. Therefore, the Student-Athlete Career Situation Inventory (SACSI; Sandstedt, Cox, Martens, Ward, Webber, \& Ivey, 2004) was created as an athlete-specific career development measure to assess variables that influence career maturity. While the revised version of the SACSI provides insight in to student-athlete career readiness (Cox, Sadberry, McGuire \& McBride, 2009), there is a dearth of information in this area which leaves several questions unanswered. First, what percentage of Division I college student-athletes are career-ready? Second, if career counseling can assist with career decision-making and exploration (Brown, 2003), yet it is underutilized (Fouad et al., 2006), what are student-athletes attitudes toward career counseling? Lastly, with college student-athlete career development being influenced by several factors, what factors determine student-athlete attitudes toward career counseling?

Investigating the career situation and attitudes toward career counseling of studentathletes at the Division I level can provide those who work with this population (e.g. athletic academic counselors, career counselors, sport psychologists) with more information to make 
informed decisions for practical application. Student-athletes who are most apt to struggle with their career development can be identified and an increased understanding of what factors influence student-athlete attitudes toward career counseling can be established. Gaining this information will allow helping professionals to better understand the career needs of studentathletes, which in turn, can lead to the creation of appropriate career development programs.

\section{Methods}

The purposes of the present study were threefold: 1) determine the career situation of male and female student-athletes attending an NCAA Division I university, 2) determine if differences existed between student-athletes and non-athlete students in their attitudes toward career counseling, and 3) determine which demographic variables, career situation factors, and personality factors (i.e. athletic identity and career locus of control) had the most influence on student-athlete attitudes toward career counseling.

\section{Instrumentation}

Demographic questionnaire. Two separate demographic questionnaires were constructed by the author to collect descriptive information from student-athletes (Appendix B) and non-athlete students (Appendix F). All participants were asked to provide their gender, age, ethnicity, academic standing, approximate grade point average (GPA), whether or not they were a first generation college students, their likelihood to use the career services center in the current semester and in the upcoming two semesters, their internship and work experience, and they were also asked to identify any career center services that they had previously used. Studentathlete participants were also asked to provide their sport, scholarship status, expectations to play their current sport at a professional level, and if they attended the student-athlete career fair the previous semester. These demographic variables were selected from relevant previous literature (Kennedy et al., 1987; Smallman et al., 1996; Kornspan et al., 2001; Cox et al., 2009). 
Student-Athlete Career Situation Inventory (SACSI). The Student-Athlete Career Situation Inventory (SACSI) was developed by Sandstedt, Cox, Martens, Ward, Webber, and Ivey (2004) as an assessment of career development and the career preparation of studentathletes. The SACSI (Sandstedt et al., 2009) is an inventory that is used as a tool to help athletic department administrators, athletic support staff, and career counselors in understanding studentathlete career development. The SACSI was later revised when it was discovered that the factor structures were different for males and females (Cox, Sadberry, McGuire, \& McBride, 2009). This revision resulted in two versions of the inventory; a 25-item SACSI-Revised Form for males (SACSI-RM; Appendix C) and a 23-item SACSI-Revised Form for females (SACSI-RF; Appendix D).

For the male version of the instrument, exploratory factor analysis (EFA) revealed five factors; Career Confidence (Factor 1; 6 items), Low Career Interests (Factor 2; 5 items), Academics/Career Important (Factor 3; 4 items), Sport Facilitates (Factor 4; 5 items), and Barriers (Factor 5; 5 items). Cronbach's $\alpha$ coefficients for the five factors were .79, .77, .70, .74, and .73 , respectively.

For women, an EFA revealed four factors; Sport Identity (Factor 1, 8 items), Career Confidence (Factor 2, 5 items), Barriers, (Factor 3; 5 items) and Sport Facilitates (Factor 4; 5 items). Cronbach's $\alpha$ coefficients for the five factors were $.79, .82, .82, .76$, respectively.

When completing this inventory, respondents were asked to answer statements pertaining to the five factors. Anchors for responses ranged from 1 (Strongly Disagree) to 5 (Strongly Agree). After some items are reversed scored, factor scores are produced by averaging the sum of item scores for each factor. High scores are desired for the positive factors 1, 3, and 4, while lower scores are preferred on the negative factors 2 and 5. 
Attitudes Toward Career Counseling Scale (ATCCS). The Attitudes Toward Career Counseling Scale (Appendix E) is a questionnaire that was created by Rochlen, Mohr, and Hargrove (1999) to measure attitudes toward career counseling by assessing the perceived value and stigma related to career counseling. The two subscales are a values scale and stigma scale. The subscales were each reduced to 8-items by retaining items with the highest variability and the largest discrepancy from an initial 36-item questionnaire. The values subscale included items relating to the perceived value and usefulness of career counseling. The stigma subscale measures shame, stigma, and negative feelings toward career counseling. Responses are made on a 6-point scale with the anchors 1 (Strongly disagree) to 4 (Strongly agree). High scores for the values subscale indicate a strong sense of value toward career counseling. A high score on the stigma subscale indicated a high degree of perceived stigma toward career counseling.

Athletic Identity Measurement Scale. The degree to which individuals identify with their role as an athlete is considered their athletic identity (Brewer, Van Raalte, and Linder, 1993). To measure athletic identity, Brewer and colleagues (1993) constructed a 10-item scale known as the Athletic Identity Measurement Scale (AIMS) to measure the affective, social, and cognitive aspects of athletes' identity. Brewer and Cornelius (2001) later revised the AIMS resulting in a 7-item measure. Participants were to respond to statements regarding their identity as they relate to athletic participation on a Likert-type scale with anchors Strongly Agree (7) to Strongly Disagree (1). Higher scores indicated a greater identification with an athlete role. The abbreviated AIMS is highly correlated $(a=.81)$ with the original 10-item AIMS. The current study utilized the abbreviated 7-item AIMS (Appendix G).

Career Locus of Control Scale. Trice, Haire, and Elliot (1989) developed the 18-item, Career Locus of Control Scale (CLCS) (Appendix H) to measure an individual's locus of control 
for career decisions. Individuals who believe that outcomes are influenced by the task difficulty, powerful others, or by chance are classified as having an external locus of control, while having a view that outcomes are dependent on one's own actions is considered an internal locus of control. Respondents were asked to identify if the presented statements were "True" or "False" for themselves. A total score (i.e. 0 to 8 ) is produced by calculating the total number of "True" responses to the statements with an external focus. Higher scores on this measure indicated more of an external career locus of control.

\section{Research Design}

The current study employed a non-experimental comparative design with Division I student-athletes and non-athlete students from the same university. Purposive sampling was utilized to recruit student-athlete participants. Convenience sampling was utilized for recruiting non-athlete students. Non-athlete student participants were students who were enrolled in undergraduate level psychology courses. The non-athlete student participants were oversampled because of the need to match non-athletes with the student-athletes sampled. Based on gender and year in school, individuals from the sample of non-athlete participants were randomly selected in order to match them with student-athletes (e.g. female senior student-athlete matched with a female senior non-athlete student).

Variables. The dependent variables in this investigation were the five factors of the SACSI-RM (career confidence, low career interest, academic/career importance, sport facilitates, and barriers), the four factors of the SACSI-RF (sport identity, career confidence, barriers, and sport facilitates), and the value and stigma subscales of the ATCCS. The factors career confidence, academic/career importance, sports facilitates were considered positive career situation factors, while the factors lack career interest, sport identity, and barriers were 
considered negative career situation factors. Mean scores for each factor of the SACSI-RM and SACSI-RF range from 1 to 5. High scores were classified as factor mean scores greater than or equal to 4 , and low scores were classified as mean scores less than or equal to 2. Career savvy student-athletes were classified as those student-athletes who scored high on the positive career situation factors, while also scoring low on the negative career situation factors (Cox et al., 2009). As for attitude toward career counseling, each subscale (values and stigma) produced a score ranging from 8 to 48 . High scores on the values subscale indicate a high degree of value toward career counseling. High scores on the stigma subscale indicate a high degree of stigma toward career counseling.

The independent variables for this study were (1) gender, (2) ethnicity, (3) academic standing, (4) grade point average (GPA), (5) first generation college student, (6) work and internship experience, (8) sport, (9) expectations to play professionally, (10) scholarship status, (11) use of services including the athlete specific career fair, (12) all of the male and female career situation factors (i.e. career confidence, sport facilitates, academic/career importance, sport identity, lack of career interest, and barriers), (13) athletic identity, and (14) career locus of control.

\section{Participants}

The participants $(N=1284)$ in this study were student-athletes $(n=354$, male $=190$, female $=164)$ and non-athlete students $(n=929$, male $=449$, female $=480)$ from a large landgrant institution in the Mid-Atlantic region of the United States. Both males $(n=639)$ and females $(n=644)$ were included in the current study. Participants in the current study met the student-athlete criteria if they were enrolled in classes at the university (i.e. part-time or fulltime) and were a current member of a varsity sport team representing the university. Non-athlete 
participants were enrolled in courses at the university (i.e. part-time or full-time) but were not current members of a varsity sport team representing the university.

The male student-athletes $(n=190)$ in the current study ranged in age from 18 to $24(M=$ 20.10, $S D=1.41$ ). Male student-athlete participants from the following teams took part of this study: football (17.5\%), baseball (10.17\%), wrestling $(9.04 \%)$, soccer $(5.56 \%)$, swimming and diving (5.65\%), and basketball (3.39\%). From this group of participants, $38.4 \%$ had received a full scholarship, 36.3\% had received a partial scholarship, and 25.3\% had not received any scholarship. A large percentage of male student-athletes (33.9\%) had GPAs ranging between $2.51-3.0$, with the second largest group (32.8\%) having GPA's ranging from $3.01-3.5$. The percentage of freshmen, sophomores, juniors, and seniors were $25.3 \%, 25.3 \%, 27.9 \%$, and $14.7 \%$, respectively. Of this group, $30.5 \%$ were first generation college students and $16.6 \%$ had taken part in an internship or job that was related to their expected future career.

The female student-athletes $(n=164)$ in this study ranged in age from 17 to $23(M=$ 19.83, $S D=1.34)$. Female student-athlete participants represented the following sports: rowing $(15.54 \%)$, cross country/track and field $(7.06 \%)$, soccer $(5.08 \%)$, swimming and diving (4.54\%), gymnastics (4.52\%), volleyball (3.95\%), basketball (3.11\%), and tennis (1.98\%). Rifle (2.82\%) was the only coed sport represented in the current study. From this group of participants, 39.6\% had received a full scholarship, $34.1 \%$ had received a partial scholarship, and $26.2 \%$ had not received any scholarship. A large percentage of female student-athletes (42.9\%) had GPAs that were 3.5 or above, with the second largest group (32.3\%) having GPA's ranging from 3.01 - 3.5. The percentage of freshmen, sophomores, juniors, and seniors were $29.9 \%, 22.0 \%, 24.4 \%$, and $18.9 \%$, respectively. Of this group, $17.7 \%$ were first generation college students and $31.6 \%$ had taken part in an internship or job that was related to their expected future. 
The participants in the non-athlete student sample $(n=929)$ ranged in age from 16 to 58 $(M=19.4, S D=2.36)$. A large percentage of this group $(33.3 \%)$ had GPA's that ranged $3.01-$ $3.5)$, with the second largest group $(25.2 \%)$ ranging from $2.51-3.0$. The percentage of freshmen, sophomores, juniors, and seniors were $58.3 \%, 23.5 \%, 10.3 \%$, and $7.5 \%$, respectively. Of this group, $28.2 \%$ were first generation college students and $25.5 \%$ had taken part in a job or internship that was relevant to their future career.

To create the matched sample, non-athlete student participants from the pool of participants $(n=929)$ were separated by gender and year in school, and were then randomly selected to be matched with a student-athlete participant of the same gender and year in school (i.e. freshman female student-athlete matched with a freshman non-athlete student). This new group of matched participants $(n=666)$ consisted of males $(n=350)$ and females $(n=316)$ that ranged in age from 16 to $28(M=19.89, S D=1.45)$. The majority of participants $(32.7 \%)$ had a GPA that ranged from $3.01-3.5$, with the second largest group $(26.3 \%)$ having GPA's ranging from $2.51-3.0$. The percentage of freshmen, sophomores, juniors, and seniors were $29.1 \%$, $25.2 \%, 26.7 \%$, and $17.7 \%$, respectively. Graduate level participants were not included in this group. Of this group, $21.8 \%$ of males and $29.7 \%$ of females were first generation college students and $29.7 \%$ of males and $35.4 \%$ of males had taken part in a job or an internship that was relevant to their future career.

\section{Procedures}

Prior to any data collection, approval from the West Virginia University Institutional Review Board (IRB) was obtained. Following IRB approval, appropriate athletic administrators were contacted via email by the primary researcher and asked for permission to collect data from the student-athletes at their university. The primary researcher then asked coaches and/or team 
staff members for permission to privately collect data from their student-athletes. Once permission was granted, the primary researcher scheduled a time for team data collection. Since some potential participants would not be able to attend team meetings, the primary researcher was granted permission to collect data from individual student-athletes in areas where studentathletes tend to frequent (e.g. study hall). All athletic teams participated in the current study.

As for the non-athlete student participants, the primary researcher contacted instructors from undergraduate psychology courses to gain permission to survey the students in their courses. Since non-athlete students would be matched with student-athletes based on gender and year in school, the primary researcher identified courses with students that could best reflect the student-athlete sample.

All instruments were administered by the primary researcher to student-athletes during individual, large group, or team settings. Coaches and other authority figures were asked not to be present during data collection. Student-athlete participants received a research packet with the following documents: 1) cover letter explaining the purpose of the study and their rights as a participant (Appendix A), 2) demographic questionnaire (Appendix B), 3) the appropriate gender specific version of the SASCI (Appendix C or Appendix D) (Cox et al., 2009), 4) the ATCCS (Appendix E) (Rochlen et al., 1999), the AIMS (Appendix G) (Brewer et al., 2001) and 5) the CLCS (Appendix H) (Trice et al., 1989). Non-athlete student participants received a research packet with the following documents 1) cover letter explaining the purpose of the study (Appendix A), 2) non-athlete student demographic questionnaire (Appendix F), and 3) ATCCS (Appendix E) (Rochlen et al., 1999). All data was entered into SPSS Version 21 by members of the research team and checked by the primary researcher. The research team consisted of four 
undergraduate sport and exercise psychology students who were trained in data entry by the primary researcher.

\section{Research Questions}

Based upon results from the pilot study, other research and the primary researcher's intuition, the following research questions were developed: 1) What percentages of male and female student-athletes meet the criteria of being career savvy?; 2) Do the variables athletic status (i.e. student-athletes and college non-athlete students) and gender (i.e. male vs. female) have an influence on attitudes toward career counseling?; and 3) Which demographic variables (e.g.year in school, GPA, sport played, internship/work experience, and expectations to play professionally), career situation factors, and personality variables (i.e. athletic identity, external career locus of control) contribute to student-athlete attitudes toward career counseling? For the first research question, it was hypothesized that $35 \%$ of male and $60 \%$ of female student-athletes would be career savvy. In relation to the second research question, it was hypothesized that student-athletes would have lower values and higher stigma scores when compared to nonathlete students and that females would have lower value scores and lower stigma scores when compared to males. No hypotheses were developed in relation to the third research question.

\section{Results}

Career savviness. To address the first research question of this study related to studentathlete career situation, it was important to determine the percentage of male and female studentathletes that met the criteria for being career savvy. For this study, an athlete was considered to be career savvy if he or she had high scores $(\geq 4.0)$ on positive career situation factors and low scores $(\leq 2.0)$ on negative career situations factors. This evaluation criterion was set by the primary researcher, as no previous standards have been set to determine "high" or "low" scores 
(Cox et al., 2009). For male student-athletes, positive career situation factors were career confidence, sport facilitates, and academic/career importance while negative factors were lack of career interest and barriers. For female student-athletes, positive career situation factors were career confidence and sport facilitates, and negative factors were sport identity and barriers. With this criterion, of the 189 male student-athletes surveyed, $1(.5 \%)$ participant met the criteria of being career savvy. Of the 164 female student-athletes surveyed, 12 (7.3\%) participants met the criteria of being career savvy. Other frequencies and percentages can be found in Table 2 .

Attitudes toward Career Counseling. The second research question which addressed the influence that the variables athletic status and gender had on attitudes toward career counseling was found by conducting two, $2 \times 2$ analyses of variance that examined the effect of the independent variables athletic status and gender on the dependent variables Values toward Career Counseling and Stigma toward Career Counseling.

The ANOVA failed to show a significant interaction between the independent variables athletic status and gender on the variable Values toward Career Counseling (see Table 4). The results of the ANOVA for the dependent variable Values toward Career Counseling yielded a main effect for the independent variable athletic status, $F(1,652)=5.029, \mathrm{p}<.05$, ES .008, such that the average Value score was significantly higher for student-athletes $(M=38.26, S D=5.86)$ than for non-athlete students $(M=37.24, S D=6.17)$. These scores indicate that student-athletes value career counseling more than non-athlete students. The Values scores for non-athlete students who were selected for the matched sample had a similar mean Stigma score as the entire non-athlete student sample $(M=37.36, S D=6.22)$. A moderately significant main effect was found for the independent variable gender $F(1,652)=58.303, \mathrm{p}<.001 ., \mathrm{ES}=.082$, indicating 
that females $(M=39.56, S D=5.43)$ reported having higher value for career counseling than males $(M=36.11, S D=6.09)$.

The results of the ANOVA did not show a significant interaction between the independent variables athletic status and gender on the variable Stigma toward Career Counseling (see Table 5). The ANOVA for the dependent variable Stigma toward Career Counseling yielded a moderate significant main effect for the variable gender $F(1,651)=62.49$, p. $<.001, \mathrm{ES}=0.08$, indicating that males $(M=20.76, S D=6.89)$ express higher stigma toward career counseling than females $(M=16.56, S D=6.67)$. No significant main effect was found for Stigma toward Career Counseling between athletes $(M=18.41, S D=6.99)$ and non-athlete students $(M=19.11, S D=7.19)$. The non-athlete students who were selected for the matched sample had a similar mean Stigma score as the entire non-athlete student sample $(M=19.17, S D$ $=7.02)$.

Predictors of attitudes toward career counseling. To determine the contribution of demographic variables, personality variables and career situation factors on values and stigma toward career counseling, four hierarchical regression analyses were performed to predict student-athlete attitudes toward career counseling (i.e. Value and Stigma). Analyses for male and female student-athletes were run separately as the instruments used to measure these attitudes contained different career situation factors.

Male student-athletes. For males, 16 independent variables were measured. These variables were categorized into four groups based on the degree of controllability by the participant. This strategy allowed the researcher to determine the contributions of career situation and personality variables, while controlling for the demographic variables. Group A (uncontrollable demographic variables) included the variables ethnicity (separated into minority 
vs. majority), academic standing, and first generation college student. Group B (controllable demographic variables) included the variables GPA, sport played, expectations to go pro, scholarship status, use of career services (including attendance to athlete specific career event), and internship/work experience. Group C included the five male SACSI factors Career Confidence, Sport Facilitates, Lack of Career Interest, Academic/Career Importance, and Barriers. Group D (personality variables) included the variables of athletic identity and career locus of control. Each group was entered independently into a regression equation for each of the dependent variables (i.e. Value toward Career Counseling and Stigma toward Career Counseling) to determine the significant contributing variables. The significant variables were retained and entered simultaneously into two separate regression equations for the dependent variables Value and Stigma.

The following variables were retained after initial analysis for the dependent variable Value toward Career Counseling: first generation college student, GPA, ethnicity, scholarship status, use of services, career confidence, lack of career interest, academic career importance, sport facilitates, and barriers. These independent variables were entered into a stepwise regression analysis to determine the contributing factors of values toward career counseling. The final model explained $18.2 \%$ of the Value toward Career Counseling scores for male studentathletes, with three predictors (see Table 6). The most significant predictor was sport facilitates, accounting for $10.3 \%(\beta=.295, \mathrm{p}<.001)$ of the variance, suggesting that those student-athletes reporting higher scores on this scale also reported higher Values scores. The second predictor was scholarship status which contributed $4.7 \%$ to the model $(\beta=.203$, p. <.05). This result suggests that male student-athletes who had less than a full scholarship were likely to report higher Value scores than those on full scholarships. The third significant variable was barriers 
which contributed $3.2 \%$ to the model $(\beta=-.179, p<.05)$, suggesting that male student-athletes reporting higher barriers scores had lower Value scores.

For the dependent variable Stigma toward Career Counseling, the following independent variables were retained following initial analysis and then included in a stepwise regression equation: GPA, use of services, academic standing, internship/work experience, career locus of control and the SACSI factors career confidence, academic career importance, and barriers. The final model explained $23.8 \%$ of the variance in Stigma toward Career Counseling scores for male student-athletes, with two significant variables (see Table 7). The most significant predictor was the SACSI factor lack of career interest accounting for $19.7 \%$ of the variance $(\beta=.399$, $p$. $<.001$ ), suggesting that male student-athletes reporting higher lack of career interest scores had higher Stigma toward Career Counseling scores. The second significant predictor was use of services, which accounted for $4.1 \%$ of the variance $(\beta=-.207, \mathrm{p} .<.05)$, suggesting that male student-athletes who utilized any of the services offered (i.e. attend career fairs, meet with a career counselor, job/internship database, online career development course) reported lower Stigma scores.

Female student-athletes. For female student-athletes, 15 independent variables were measured. These variables were categorized into four groups similar to those of male studentathletes except for Group C which included the four female SACSI factors Career Confidence, Sport Identity, Sport Facilitates, and Barriers. Each group was entered independently into a regression equation for each of the dependent variables (i.e. Value and Stigma) to determine the significant contributing variables. The significant variables were retained and entered simultaneously into two separate regression equations for the dependent variables Value and Stigma. 
The retained variables from the initial analysis of the dependent variable Value were: academic standing, expectations to go pro, use of services, athletic identity, and the SASCI factors career confidence and sport facilitates. These variables were entered into a stepwise regression equation. The final model explained $10.3 \%$ of the variance in Value scores for female student-athletes, with one significant predictor (see Table 8). The most significant predictor was sports facilitates $(\beta=.322, \mathrm{p} .<.001)$, suggesting that female student-athletes reporting high sport facilitates scores also reported higher value scores. Individuals with high sport facilitates score believe their sport involvement would provide them with skills that are transferrable to their future careers.

The following variables were retained after initial analyses of the dependent variable Stigma: academic standing, use of services, athletic identity, career locus of control and the SACSI factors career confidence, sport facilitates, sport identity, and barriers. The aforementioned independent variables were entered into a stepwise regression to determine predictors for the dependent variable Stigma. The final model explained $18.3 \%$ of the variance in Stigma scores for female student-athletes, with three significant variables (see Table 9). The most significant predictor was career locus of control, accounting for $11.5 \%$ of the variance $(\beta=$ $.266, \mathrm{p} .=.001)$, suggesting that female student-athletes with higher CLCS scores (i.e. external career locus of control) reported higher Stigma scores. The second predictor was sport identity, accounting for $4.4 \%$ of the variance $(\beta=2.17, \mathrm{p} .<.05)$, suggesting that female student-athletes reporting high sport identity scores also reported higher Stigma scores. The third predictor was sport facilitates, accounting for $2.3 \%$ of the variance $(\beta=-.153$, p. $<.05)$, suggesting that female student-athletes reporting low sport facilitates scores also reported lower Stigma scores. 


\section{Discussion}

The results of this investigation provide insight into the career situation of Division I student-athletes. The results also show that student-athletes in the current sample valued career counseling more than the non-athlete students and that females reported having higher value for career counseling than males. Males were also found to express a higher degree of stigma toward career counseling than females. The results of the regression analyses provide evidence about which career situation factors, demographic variables, and personality factors contributed to student-athlete attitudes toward career counseling. The findings of this study will help professionals who work with this population to better assist and meet the career development needs of student-athletes.

\section{Student-athlete career situation}

Career Savviness. The first research question was directed at determining the career savviness of Division I male and female student-athletes. A career savvy student-athlete has an awareness of his or her ability to complete career development tasks, gives enough attention to career development and academics, understands that sports provide skills that will help in a career, and does not believe that their athletic commitment takes away from career related tasks. Only $13(3.7 \%)$ student-athletes (1 Male, 12 Females) in this sample $(n=353)$ met the criteria of being career savvy. One possible explanation for this limited number of career savvy athletes is that the criterion was set too stringently. Instead of setting a criterion for student-athletes needing to meet the criteria for all of the career situation factors, maybe they should have been expected to meet the criteria for the majority of the factors. If the criterion was adjusted in this fashion, only 46 male student-athletes would have met the scoring criteria for at least 3 of the 5 male career situation factors, while 55 female student-athletes would have met the scoring criteria for at least 3 of the 4 career situation factors. 
It is also possible that the low percentage of student-athletes meeting the established criteria in the current study is an indication that division I student-athletes are not career savvy or that the actual scoring criteria (i.e. $\geq 4.0$ on the positive career situation factors, $\leq 2.0$ on the negative career situation factors) set by the researcher for each of the factors was too stringent. Unfortunately, previous researchers have not identified cut scores for determining career savvy behaviors for the scale scores of the SASCI. Since the SASCI (Cox et al., 2009) had a "Neutral" anchor represented by a score of 3.0, the cut off score of 4.0 was chosen because individuals who report scores at or above this score on the positive factors express more certainty in their beliefs about themselves rather than being indifferent. The cut score of 2.0 was chosen because individuals who report scores at or below this score on the negative factors express more certainty in their beliefs about themselves rather than being indifferent. Previous findings from Cox and colleagues (2009) had the following mean scores for the male career situation factors career confidence, lack of career interest, academic career importance, sport facilitates, and barriers 3.6, 3.52, 3.25, 3.84, and 2.84, respectively. Female career situation mean scores for sport identity, career confidence, barriers, and sport facilitates were 3.94, 3.76, 3.06, and 4.04, respectively. From the male and female factors, only the mean score for the female career situation factor sport facilitates would have met the scoring criteria for the current study (i.e. $\geq 4$ ). This finding helps to support the contention that Division I collegiate student-athletes may not be very career savvy.

It was hypothesized that upwards of $35 \%$ of male and $60 \%$ of female student-athletes would be career savvy based on the efforts made by the university's career center and the athletic department to introduce new career development programs to their student-athletes. However, the career situation factor barriers had the lowest percentage of male $(6.9 \%)$ and female $(16.5 \%)$ 
student-athletes who reported scores that met the set criteria (i.e. scores $\leq 2.0$ ). Having few participants who met this one criterion significantly decreased the possibility of student-athletes meeting all of the criteria for being classified as career savvy. The lifestyle of student-athletes can serve as a barrier to their career development. Having to manage classes, homework and studying, practices, travel, weight training, and then finding time to attend career related events may not be an easy task for student-athletes (Potuto et al., 2006; Watt \& Moore, 2001). While several researchers have cited limited time as a reason why student-athletes do not partake in career development activities (Brown et al., 2000; Carodine et al., 2001, Rochlen et al., 2002a), others have noted that other internal and external barriers may exist (Coleman \& Barker, 1993), and proximity of services can determine student-athletes use (Jordan \& Denson,1990).

It is also important to consider the impact that the university's entrance requirements and the university's culture may have on the career development of student-athletes and non-athlete students. As a land-grant institution, prospective in-state students need to have a minimum GPA of 2.0 and either a composite ACT score of 19 or a combined Math and Critical Reading SAT score of 910 to have their application reviewed, while non-residents need scores of $2.5,21$, or 990 , respectively. These standards could lead to students being granted admission who may not be prepared academically, which could lead to them not being focused on their career development. Of the 2,519 freshmen students who were admitted to the university in $2007,28 \%$ graduated within four years and 53\% graduated within six years, which illustrates that students may not be prepared for college and thus take longer to complete their degree. However, the completion of an academic program does not equal career readiness or career savviness, but engaging in career related tasks (e.g. workshops, career fairs, and internships) does increase career maturity. Of the 929 non-athlete students in the current study, only $25.5 \%$ 
have had some type of work or internship experience that is related to their future career.

Additionally, only $16.6 \%$ of male student-athletes had relevant work or internship experience, but surprisingly, $31.6 \%$ of female student-athletes had an internship or work experience that was related to their future career.

The findings in the current study illustrate that student-athletes are not career savvy and previous literature supports that they have several potential and perceived barriers when it comes to their career development. From this perspective, it is clear that programs should be created in collaboration between athletic departments and Career Centers to develop programs that will improve upon the career development of student athletes. Such programs need to address the systemic issues which serve to delay student athlete career development.

\section{Attitudes toward career counseling}

Values toward career counseling. It was hypothesized that Division I student-athletes would have lower values towards career counseling scores when compared to non-athlete students. While there has been no previous research that compares these two groups and their values toward career counseling, this hypothesis was formulated from similar literature regarding attitudes toward help seeking behaviors (Watson et al., 2005). Surprisingly, the aforementioned hypothesis was not supported, rather, the results of this study show that student-athletes had significantly higher value scores than non-athlete students. A possible rationale could be that student-athletes envision career counseling as being similar to other student help services (e.g. tutoring, athletic academic advisors, nutritionist, sport psychology) that are already provided by their athletic department. If student-athletes have found value in these other services or have experienced positive results following their use, the likelihood of using career counseling services in the future, or recommending them to other athletes, could increase. 
It was also hypothesized that females (student-athletes and non-athlete students) would have higher value toward career counseling scores when compared to males. This hypothesis was confirmed, indicating that females valued career counseling more than males. This finding is Furthermore, Rochlen and O'Brien (2002a) explained that males tend to use career counseling only if they believe they need professional advice for general career assistance, need help with job placement, or if they want to increase their career options. This is due in part to men often being conditioned to solve problems on their own in order to decrease the possibility of appearing as weak or vulnerable (Rochlen et al., 2002a).

In two separate stepwise regressions for male and female student-athletes, the career situation factor sport facilitates was the most significant predictor, accounting for $10.3 \%$ of the variance. This factor indicates that student-athletes believe sport helps to provide them with skills that can be transferred to the world of work. Several researchers have also addressed transferable skills being associated with athlete career transitions (Danish, Petitpas, \& Hale, 1993; Hearle, 1975; Pearson \& Petitpas, 1990; Petitpas, Danish, McKelvain, and Murphy, 1992). The findings in the current study suggest that student-athletes who believe their sport can provide them with transferable skills also value career counseling. Having an awareness of such skills could be an indicator that these student-athletes are thinking about their future career and see career counseling as a beneficial resource.

Although scholarship status and barriers were statistically significant predictors of values toward career counseling, their influence was rather weak. Scholarship status entered the regression equation second, accounting for $4.7 \%$ of the variance in value toward career counseling, and barriers entered the equation last accounting for $3.2 \%$ of the variance. While there is no previous literature relating to scholarship status, the current results suggest that male 
student-athletes who are not on a full scholarship give more value to career counseling. Studentathletes who are not on scholarship may believe that the use of career counseling can assist with their future endeavors since their chance of playing sports professionally are more slim than those on scholarship. In terms of barriers, several studies have cited that athletic participation creates time constraints that have a negative influence on aspects of student-athlete's career development (Brown et al., Carodine et al., 2001; Potuto and O’Hanlon, 2006; Watt \& Moore, 2001). The present results provide some evidence to suggest that male student-athletes who believe that their athletic involvement takes away from their career development do not value career counseling.

Stigma toward career counseling. It was hypothesized that Division I student-athletes would have higher stigma scores when compared to non-athlete students, however, in the current study there were no significant findings to support this hypothesis. Reported stigma scores for both groups were low, which could be attributed to the high value scores that were reported by these two groups. Similarly, Rochlen and colleagues (1999) found that having high values scores were linked to low stigma scores. It was also hypothesized that females would have lower stigma scores when compared to males. This hypothesis was confirmed, indicating that females had lower levels of stigma toward career counseling than males. The findings of the current study are consistent with previous literature from researchers who examined the relationship of gender and stigma toward career counseling (Rochlen et al., 1999; Ludwikoski, Vogel, \& Armstrong, 2009).

To determine predictor variables of stigma toward career counseling, regression analyses were conducted separately for male and female student-athletes. For male student-athletes, the factor lack of career interest, which represents the limited attention that is given to the career 
development process, entered the regression equation first, accounting for $19.7 \%$ of the variance in stigma toward career counseling. This finding is similar to Lally and Kerr (2005) in that they found that student-athletes did not begin to focus on their academics or career path until they came to the realization that a professional athletic career was not in their future. It could be that male student-athletes who have a lack of career interest have an aversion to career counseling due to embarrassment or being ashamed of their chosen career path, or lack thereof. Or, that male student-athletes hold on to their dreams of playing professionally longer than females as a result of the increased opportunities for males to compete professionally.

The variable use of service (including athlete specific career fair) entered the regression equation last, accounting for $4.1 \%$ of the variance in stigma toward career counseling. This variable denotes an athlete's use of services provided by the university's career center, including an athlete specific career forum. The negative correlation indicates that those male studentathletes who use services were more likely to have less stigma toward counseling. Similarly, Rochlen and colleagues (1999) found that college students who had previous career counseling experiences reported lower level of stigma toward career counseling. The findings of the current study show that the more male student-athletes utilized the provided career services, including athletic specific career events, their stigma toward career counseling decreased. This result could help explain why previous researchers have recommended that career programs and career counseling should be tailored to meet the specific needs of athletes (Lenz et al., 2003; Stankovich et al., 2001; Witmer et al., 1981; Wooten et al., 1994).

The most significant predictor of female student-athlete stigma toward career counseling was career locus of control, which accounted for $11.5 \%$ of the variance. The current findings add to previous literature which has found career locus of control to be a predictor of student and 
student-athlete career maturity (Kornspan et al., 2001; Luzzo, 1995; Sandstedt et al., 2004). The results indicated that a positive correlation exists between CLCS scores and stigma scores, suggesting that female student-athletes with a strong external locus of control have more aversion to career counseling. Similar to Bandura's (1977) self-efficacy theory, those with an external locus of control will believe that they do not have control over their futures and may put less effort into their career preparation (Trice et al., 1989). A female student-athlete with this type of mentality may not even consider seeking career counseling or may find reasons why career counseling would not be beneficial for her.

The second predictor of female student-athlete stigma toward career counseling was sport identity, accounting for $4.4 \%$ of the variance. A student-athlete with a high sport identity is focused more on athletics than career related issues (Cox et al., 2009). The findings of this study support literature from Murphy, Petitpas, and Brewer (1996) who found that student-athletes with higher athletic identities were less likely to engage in career development activities (e.g. seeking career counseling). Female student-athletes with high sport identities are likely to have a high degree of stigma toward career counseling. These female student-athletes may identify more with their athlete role and seeking career counseling could give the perception that they are not fully committed to their sport or they could be admitting that they are no longer athletes. Therefore, female student-athletes wanting to avoid the negative perceptions from others may not seek career counseling.

The third predictor of female student-athlete stigma toward career counseling was the career situation factor sport facilitates, accounting for $2.3 \%$ of the variance. In the current study, Sport facilitates was a contributing factor to both male and female value toward career counseling. Student-athletes in the Potuto and O'Hanlon's (2006) study believed their athletic 
participation assisted in the development of their leadership skills, teamwork ability, work ethic, ability to make decisions, time management, and their ability to take responsibility for self and others. These qualities and characteristics are not only valued within the realm of athletics, but they are also applicable to the working world. The findings in the current study show that female student-athletes who believe that their athletic participation can prepare them for the working world had lower levels of stigma toward career counseling.

\section{Practical implications}

The results of this study provide evidence to suggest that a majority of student-athletes did not meet the criteria of being career savvy, they believe that their sport participation will help them in their future career, but their athletic commits also hinder their career development. While these findings may seem complex, they are no different than findings from studies that date back to the early 1980's and have remained prominent for more than 30 years (Linnemeyer et al.,, 2010; Martens et al., 2000; Wittmer et al., 1981).

Therefore, if student-athlete development is an important part of university athletic programs, certain steps need to be taken in order to improve upon career development of studentathletes. The first step in changing this likely resides in athletic administrators and coaches working together to integrate career development components into their athletic programs as a means to prepare their student-athletes for careers after graduation. Compared to previous years, an increasing number of student-athletes are graduating from college and they are doing so at a higher rate than non-athlete students (Petr et al, 2012). Only a small percentage of these athletes will move on to play their sports professionally (NCAA, 2012a), meaning they will have to pursue a career in something other than sport. If student-athletes are not prepared for life after graduation, they may face career transition problems (Coakley, 1983). To help decrease this 
problem, career center personnel could give the SACSI to all student-athletes. These results would help identify student-athletes who may not be career savvy and would be considered appropriate referrals to career counselors. This information could also be used as a guide to determine what career programs or workshops might be best for their student-athlete population.

Athletic departments should also consider having a specific department or staff member who specializes in career development specifically with athletes. Some universities have adopted this approach and have noticed positive changes in the career development of their student-athletes (Lenz et al., 2003; Stankovich et al., 2001). This approach illustrates to the student-athlete that the athletic department takes student-athlete career development seriously. Having someone who works in close proximity or within athletic facilities could increase use of services (Jordan et al., 1990) and decrease the stigma and increase the perceived value of utilizing such services (Rochlen et al., 2002; Rochlen et al., 2002a). Having a professional imbedded in the athletic department can also help to make the career counseling process clearer and applicable to the student-athletes and their schedules, can work with coaches to have this information imbedded within the team structure, and would also allow for more personal relationships to develop over time (Jordan et al., 1990).

\section{Limitations}

The results of the current study should be interpreted with caution due to certain limitations. Although the sample size of student-athletes $(n=354)$ and non-athlete students $(n=$ 930) was sufficient for the analyses, all data was collected from students on a single university campus. Therefore, the results of the study may not be generalizable to other student-athletes and non-athlete students attending other universities. However, having results from these groups 
gives the athletic department and the career center a glimpse into the student-athlete career situation and their attitudes toward career counseling.

Another limitation of the current study could be social desirability within the responses of the athletes. Given that the primary researcher has conducted career development workshops and engaged in individual career counseling sessions with members of the student-athlete population, the participants could have answered in a manner that was not an actual description of themselves or their beliefs as a means of trying to accommodate the researcher's wishes and/or needs.

\section{Future research}

Although the current study has some limitations, the findings from this study can serve as a framework for future student-athletes' career development programs in addition to identifying other areas that need further explanation. Future research should explore the concept of studentathlete career savviness since previous researchers have yet to provide a cutoff score to differentiate between "high" and "low" scores for the career situation factors (Cox et al., 2009). In the current study, only a few student-athletes were considered to be career savvy and it has not been determined if this is due to stringent criterion set by the researcher or if the student-athletes in this study are simply not career savvy because of the role that athletics plays in their lives. To give clarity to this issue, administering the SACSI to student-athletes who are attending universities across the nation would improve the validation of the instrument and could help to better establish classification criteria for determining career savvy student-athletes. In the present study, student-athletes had to meet predetermined scores for all of the career situation factors to be considered career savvy. However, the establishment of different criteria might help to change this criterion. With further clarification, it would also be interesting to observe if 
career savviness differs between student-athletes who attend universities that have career development centers as a part of their athletic department and those that do not.

In terms of attitudes toward career counseling, it would be helpful to understand why student-athletes do not utilize career services, why they choose to use certain services more than others, and what would increase their likelihood to utilize provided career services in the future? Both male and female student-athletes in the current study utilized career fairs more than any other provided service. Conducting qualitative research to better understand and answer these questions would help to better guide athletic departments and career services personnel on how to establish programs that will best meet the needs of student-athletes. 


\section{References}

Adler, P., \& Adler, P.A. (1980). From idealism to pragmatic detachment: The academic performance of college athletes. Sociology of Education, 58(4), 241-250.

Bandura, A. (1977). Self-efficacy: Toward a unifying theory of behavioral change. Psychological Review, 84, 191-215

Beamon, K.K. (2008). “Used goods”: Former African-American college student-athletes' perception of exploitation by division I universities. Journal of Negro Education, 77(4), 352-364.

Brewer, B.W., \& Cornelius, A.E. (2001). Norms and factorial Invariance of the athletic identity measurement scale (AIMS). The Academic Athletic Journal, 15, 103-113.

Brewer, B.W., Van Raalte, J.L., \& Linder, D.E., (1993). Athletic Identity: Hercules' muscles or achilles' heel? International Journal of Sport Psychology, 24, 237-254.

Brown, D. (2003). Career information, Career Counseling, and Career Development ( $8^{\text {th }}$ ed.) Boston, MA; Allyn and Bacon.

Brown, C., Glastetter-Fender, C., \& Shelton, M. (2000). Psychosocial Identity and Career Control in College Student-Athletes Journal of Vocational Behavior 56, Issue 1, 53-62.

Bui, K.V.T. (2002). First-generation college students at a four-year university: Background characteristics, reasons for pursuing higher education, and first-year experiences. College Student Journal, 36(1), 3.

Carodine, K., Almond, K.F., \& Gratto, K. (2001). College student athlete success both in and out of the classroom. New Directions for Student-Services, 2001(93), 19-33.

Coleman, V.D., \& Barker, S.A. (1991). A model of career development for student-athletes. The Academic Athletic Journal, 33-40.

Coakley, J.J. (1983). Leaving competitive sport: Retirement or rebirth. Quest, 35, 1-11. 
Cook, E.P. (1984). Students' perception of personal problems, appropriate help sources, and general attitudes about counseling. Journal of College Student Personnel, 25, 139-145.

Crites, J.O. (1961). A model for the measurement of vocational maturity. Journal or Counseling Psychology, 8(5), 255-259.

Danish, S.J., Petitpas, A.J., \& Hale. (1993). Life development intervention for athletes: Life skills through sports. The Counseling Psychologist, 21(3), 352-385.

Etzel, E. F., Watson, J., \& Gardner, F. L. (2007). Ethical challenges for psychological consultations in intercollegiate athletics. Journal of Clinical Sport Psychology, 1(3), 304317.

Fischer, E.H., \& Farina, A. (1995). Attitudes toward seeking professional psychological help: A shortened form and considerations for research. The Journal of College Student Development, 36(4), 368-373.

Fouad, N.A., Guillen, A., Harris-Hodge, E., Henry, C., Novakovic, A. Terry, S., \& Kanatamneni, N. (2006). Need, awareness and use of career services for college students. Journal of Career Assessment, 14(4), 407-420.

Hansen, J. C. (1974). Test review: J. O. Crites, Career Maturity Inventory. Journal of Counseling Psychology, 21(2), 168-172.

Jordan, J.M., \& Denson, E.L. (1990). Student services for athletes: A model for enhancing the student-athlete experience. The Journal of Counseling Development, 69, 95-97.

Kelly, A.E., \& Achter, J.A. (1995). Self-concealment and attitudes toward counseling in university students. Journal of Counseling Psychology, 42, 40-46. 
Kennedy, S. R., \& Dimick, K. M. (1987). Career maturity and professional sports expectations of college football and basketball players. Journal of College Student Personnel, 28(4), $293-$ 297.

Knight Commission on Intercollegiate Athletics. (2001). A call to action: Reconnecting college sports and higher education.

Kornspan, A.S., \& Etzel, E.F. (2001). The relationship of demographic and psychological varisbles to career maturity of junior college student-athletes. Journal of College Student Development, 42(2), 122-132.

Lally, P., \& Kerr, G, (2005). The career planning, athletic identity, and student role identity of intercollegiate student athletes. Research Quarterly for Exercise and Sport, 76, 275-285.

Lenz, J.G., \& Shy, J.D. (2003). Career services and athletics: Collaborating to meet the needs of student-athletes. NACE Journal, 63(3), 36-41.

Letawsky, N.R., Schneider, R.G., Pedersen, P.M., \& Palmer, C.J. (2003). Factors influencing the college selection process of student-athletes: Are their factors similar to non-athletes. College Student Journal, 37(4), 604-610.

Linnemey, R.M., \& Brown, C. (2010). Career maturity and foreclosure in student athletes, fine arts students, and general college students. Journal of Career Development, 37(3), 616634.

Ludwikoski, W.M.A., Vogel, D., \& Armstrong, P.I. (2009). Attitudes toward career counseling: The role of public and self-stigma. Journal of Counseling Psychology, 56(3), 408-416.

Luzzo, D.A. (1995). The relative contributions of self-efficacy and locus of control to the prediction of career maturity. Journal of College Student Development, 36 (1), 61-66. 
Marcia, J.E. (1966). Development and validation of ego-identity status. Journal of Personality and Social Psychology, 3(5), 551-558.

Medalie, J.M. (1981). The college years as a mini-life cycle: Development tasks and adaptive options. Journal of American College Health Association, (30)2, 75-79.

Martens, M.P., \& Cox, R.H. (2000). Career Development of College Varsity Athletes. Journal of College Student Development, 41(2), 172-179.

Meeker, D., \& Stankovich, C. (1999). Positive transitions programs prepares student-athletes after the cheering stops. Athletics Administration, 34-35.

Murphy, M., Petitpas, A.J., \& Brewer, B.W. (1996). Identity foreclosure, athletic identity, and career maturity in intercollegiate athletes. The Sport Psychologist, 10, 239-246.

National Collegiate Athletic Association (NCAA, 2011). Examining the student-athlete experience through the NCAA GOALS and SCORES studies. NCAA Convention. January 13, 2011. San Antonio, TX.

National Collegiate Athletic Association (September 17: NCAA, 2012a). Probability of competing in athletics beyond high school. Retrieved December 18, 2012 from http://www.ncaa.org/wps/wcm/connect/public/ncaa/resources/research/probability+of+go $\underline{\text { ingtpro }}$.

Naylor, N. (1983). Career planning for student athletes. AGB Reports, 25(6), 21-29.

Paskus, T.S. (2012). A summary and commentary on the quantitative results of current NCAA academic reforms. Journal of Intercollegiate Sport, 5, 41-53.

Parker, K.B. (1994). "Has-beens" and "Wanna-bes": Transition experiences of former major college football players. The Sport Psychologist, 8, 287-304. 
Pearson, R.E., \& Petitpas, A.J. (1990). Transitions of athletes: Developmental and preventative perspectives. Journal of Counseling \& Development, 69, 7-10.

Petitpas, A., Danish, S., McKelvain, R, \& Murphy, S. (1992). A career assistance program for elite athletes. Journal of Counseling \& Development 70, 383-386.

Petr, T.A., \& McArdle, J.J. (2012). Academic research and reform: A history of the empirical basis for NCAA academic policy. Journal of Intercollegiate Sport 5, 27-40.

Petr, T.A., \& Paskus, T.S. (2009) The Collection and use of academic outcomes data by the NCAA. New Directions for Institutional Research, 144, 77-92.

Potuto, J.R., \& O’Hanlon, J. (2007). National study of student-athletes regarding their experiences as college students. College Student Journal, 41(4), 947-966.

Purdy, D.A., Eitzen, D.S., \& Hufnagel, R. (1982). Are athletes also students? The education attainment of college athletes. Social Problems, 29(4), 439-448.

Rochlen, A.B., Mohr, J.J., \& Hargrove, B.K. (1999). Development of the attitudes towards career counseling scale. Journal of Counseling Psychology, 46(2), 196-206.

Rochlen, A.B., \& O’Brien, K. M. (2002a). Men's reasons for and against seeking help for career related concerns. Journal of Men's Studies, 11(1), 55-63.

Rochlen, A.B., Blazina, C., \& Raghunathan, R. (2002). Gender role conflict, attitudes toward career counseling, career decision-making, and perceptions of career counseling advertising brochures. Psychology of Men \& Masculinity, 3(2), 127-137.

Sandstedt, S.D., Cox, R.H., Martens, M.P., Ward, D.G., Webber, S.N., \& Ivey, S. (2004). Development of the Student Athlete Career Situation Inventory. Journal of Career Development, 31, 79-93. 
Smallman, E., \& Sowa, C. J. (1996). Career maturity levels of male intercollegiate varsity athletes. Career Development Quarterly, 44(3), 270 -277.

Stankovich, C.E., Meeker, D.J., \& Henderson, J.L. (2001). The positive transition model for sport retirement. Journal of College Counseling, 4, 81-84.

Super, D., Crites, J., Hummel, R., Moser, H., Overstreet, P., \& Warnath, C. (1957b). Vocational Development: A framework for research. Teachers College, Columbia University. American Book-Stratford Press, Inc., New York.

Taylor, K.M., \& Betz, N.E. (1983). Applications of Self-efficacy theory to the understanding and treatment of career indecision. Journal of Vocational Behavior, 22, 63-81.

Underwood, J. (1980). The writing is on the wall. Sports Illustrated, 52(21), 36-71.

Watson, J.C. (2005). College student-athletes' attitudes toward help-seeking behavior and expectations of counseling services. Journal of College Student Development, 46(4), 442-449.

Watt, S.K., \& Moore III, J.L. (2001). Who are student athletes? New Directions for Student Services, 93, 7-18.

Wittmer, J., Bostic, D., Phillips, T.D., \& Waters, W. (1981). The personal, academic, and career problems of college student athletes: Some possible answers. The Personnel and Guidance Journal, September, 52-55.

Wooten, H.R., \& Hinkle, J.S. (1994). Career life planning with college student-athletes. TCA Journal, 22, 35-39 


\section{Tables}

\section{Table 1}

Research Questions (RQ) and Hypothesis (HYP)

RQ1 What percentage of male and female student-athletes are considered career savvy?

H1a. Of Division I Male student-athletes, less than $35 \%$ will meet the criteria for being career savvy (i.e. scoring high $(\geq 4)$ on the career situation factors career confidence, sports facilitates, and academic/career importance, while also scoring low $(\leq 2)$ on the variables lack career interest, and barriers).

H1b. Of Division I female student-athletes, at least $60 \%$ will meet the criteria for being career savvy (i.e. scoring high on the career situation variables career confidence, sports facilitates, while scoring low on the variables sport identity, and barriers).

RQ2 Do Division I student-athletes and college non-athlete students differ in their attitudes toward career counseling? Do males and females differ in their attitudes toward career counseling?

H2a. Division I student-athletes will have lower values scores and higher stigma scores when compared to non-athlete students.

H2b. Females (student-athletes and non-athlete students) will have lower value scores and lower stigma scores when compared to males (student-athletes and non-athlete students).

RQ3 Which demographic variables (i.e. ethnicity, academic standing, grade point average (GPA), first generation college student, work and internship experience, 
sport, expectations to play pro, scholarship status, and use of services including the athlete specific career fair), career situation factors, and personality factors (i.e. athletic identity, career locus of control) contribute to student-athlete's attitudes toward career counseling.

\section{Table 2}

Frequencies and Percentages regarding student-athletes career savviness

\begin{tabular}{lcrcr}
\hline & \multicolumn{2}{c}{ Male $(n=189)$} & \multicolumn{2}{c}{ Female $(n=164)$} \\
\cline { 2 - 5 } Number of Career Savvy Criteria Met & $\#$ & $\%$ & $\#$ & $\%$ \\
\hline 0 & 37 & 19.6 & 24 & 14.6 \\
1 & 64 & 33.9 & 43 & 26.2 \\
2 & 42 & 22.2 & 42 & 25.6 \\
3 & 34 & 18.0 & 43 & 26.2 \\
4 & 11 & 5.8 & $12 *$ & 7.3 \\
5 & $1 *$ & 0.5 & &
\end{tabular}

Note. $*$ denotes student-athletes who met the specified criteria of being career savvy (i.e. scoring $\geq 4.0$ on positive career situation factors and scoring $\leq 2.0$ on negative career situation factors)

\section{Table 3}

Means and Standard deviations of student-athlete career situation factors

\begin{tabular}{lcccc}
\hline & \multicolumn{2}{c}{ Male $(n=190)$} & \multicolumn{2}{c}{ Female $(n=164)$} \\
\cline { 2 - 5 } SACSI Factors & $M$ & $S D$ & $M$ & $S D$ \\
\hline Career Confidence & 3.67 & .61 & 3.74 & .68 \\
Lack of Career Interest & 2.50 & .75 & & \\
Academic Career Importance & 3.25 & .78 & & \\
Sport Facilitates & $4.06^{*}$ & .59 & $4.06^{*}$ & .69 \\
Barriers & 3.02 & .67 & 2.98 & .82 \\
Sport Identity & & & $1.98^{*}$ & .68 \\
\hline
\end{tabular}

Note. $*$ denotes factors that met the specified criteria of being $\geq 4.0$ or $\leq 2.0$ 
Table 4

Analysis of Variance for ATCCS Value subscale

\begin{tabular}{lccccc}
\hline Variables & $M$ & $S D$ & $d f$ & $F$ value & $p$ \\
\hline Athletic Status & & & 1 & 5.029 & $.025^{*}$ \\
$\quad$ Student-Athlete & 38.26 & 5.86 & & & \\
$\quad$ Non-athlete Student & 37.24 & 6.16 & & & \\
Gender & & & 1 & 58.303 & $.000^{* *}$ \\
$\quad$ Male & 36.11 & 6.09 & & & \\
$\quad$ Female & 39.56 & 5.43 & & & \\
Athletic Status by Gender & & & & .04 & .843 \\
\hline $\begin{array}{l}\text { Note. } N=656 . \text { ATCCS Value subscale maximum score }=48 \\
* * 01\end{array}$ & & & & & \\
$* p<.05$ & & & & & \\
& & & & & \\
\end{tabular}

\section{Table 5}

Analysis of Variance for ATCCS Stigma subscale

\begin{tabular}{lccccc}
\hline Variables & $M$ & $S D$ & $d f$ & F value & $p$ \\
\hline Athletic Status & & & 1 & 1.737 & .188 \\
$\quad$ Student-Athlete & 18.41 & 6.99 & & & \\
$\quad$ Non-athlete Student & 19.11 & 7.18 & & & \\
Gender & & & 1 & 62.488 & $.000^{* *}$ \\
$\quad$ Male & 20.76 & 6.89 & & & \\
$\quad$ Female & 16.56 & 6.67 & & & \\
Athletic Status by Gender & & & 1 & 0.107 & .074 \\
\hline
\end{tabular}

Note. $N=656$. ATCCS Stigma subscale maximum score $=48$

$* * p<.01$ 
Table 6

Regression Analysis for the prediction of Male Student-Athlete Value

\begin{tabular}{lccc}
\hline Predictor variables & Beta & $\boldsymbol{R}^{2}$ Change & $\boldsymbol{F}$ \\
\hline Sport facilitates & .295 & .103 & $.000^{* *}$ \\
Scholarship Status & .203 & .047 & $.002^{* *}$ \\
Barriers & -.179 & .032 & $.009 * *$ \\
First generation College & .027 & & .705 \\
student & .016 & & .826 \\
GPA & .013 & & .867 \\
Ethnicity & .086 & & .234 \\
Use of Service (including & .052 & & .484 \\
ACF) & -.088 & & .214 \\
Career Confidence & .112 & & .127 \\
Lack of career interest & & \\
Academic Career importance & & \\
\hline
\end{tabular}

Note. $N=183 ; \mathrm{ACF}=$ Athlete Career Fair

** $p<.01$

Table 7

Regression Analysis for the prediction of Male Student-Athlete Stigma

\begin{tabular}{lccc}
\hline Predictor variables & Beta & $\boldsymbol{R}^{2}$ Change & \multicolumn{1}{c}{} \\
\hline Lack of career interest & .399 & .197 & $.000^{* *}$ \\
Use of Service (including & -.207 & .041 & $.002 *$ \\
ACF) & -.049 & & .505 \\
Grade Point Avg. (GPA) & -.084 & & .240 \\
Career Confidence & .050 & & .485 \\
Academic Career importance & .054 & & .418 \\
Barriers & -.028 & & .691 \\
Academic Standing & .057 & .434 \\
Internship/Work experience & .119 & .100 \\
CLCS & & \\
\hline
\end{tabular}

Note. $N=179$; CLCS = Career Locus of control; ACF = Athlete Career Fair

** $p<.01$ 
Table 8

Regression Analysis for the prediction of Female Student-Athlete Value

\begin{tabular}{lccc}
\hline Predictor variables & Beta & $\boldsymbol{R}^{2}$ Change & $\boldsymbol{F}$ \\
\hline Sport facilitates & .322 & .103 & $.000^{* *}$ \\
Academic Standing & .90 & & .230 \\
Pro Expectation & -.099 & .198 \\
Use of Service & .139 & & .067 \\
(including ACF) & .094 & & .236 \\
AIMS & .134 & .086 \\
Career Confidence & & \\
\hline
\end{tabular}

Note. $N=157$; ACF = Athlete Career Fair; AIMS = Athletic Identity

$* * p<.01$

Table 9

Regression Analysis for the prediction of Female Student-Athlete Stigma

\begin{tabular}{lccc}
\hline Predictor variables & Beta & $\boldsymbol{R}^{2}$ Change & $\boldsymbol{F}$ \\
\hline CLCS & .266 & .115 & $.001^{* *}$ \\
Sport Identity & .217 & .044 & $.006^{* *}$ \\
Sport Facilitates & -.153 & .023 & $.038^{*}$ \\
Academic Standing & -.137 & & .072 \\
Use of Service & -.081 & & .300 \\
(including ACF) & .033 & & .711 \\
AIMS & -.008 & & .927 \\
Career Confidence & .089 & & .256 \\
Barriers & & & \\
\hline
\end{tabular}

Note. $N=162 ;$ CLCS $=$ Career Locus of control; $\mathrm{ACF}=$ Athlete Career Fair; AIMS = Athletic Identity

$* * p<.01$

$* p<.05$ 


\section{Appendices}

Appendix A

Participant Cover Letter

\section{Dear Participant,}

This letter is a request for you to take part in the quantitative phase of a mixed method research study regarding the career development preparation of college student-athletes and non-athlete college students. This study is being conducted by Adrian Ferrera, a Sport and Exercise Psychology Doctoral student in the College of Physical Activities and Sport Sciences under the supervision of Dr. Jack Watson a Professor in Sport and Exercise Psychology at West Virginia University. The West Virginia University Institutional Review Board (IRB) has acknowledgement of this study on file.

Your participation in this study is greatly appreciated and should take approximately 20 minutes to complete the following research packet. Enclosed in this packet you will find a demographics questionnaire, the Attitudes Toward Career Counseling Scale (ATCCS; Rochlen, 1999), and if you are a student-athlete, the gender appropriate version of the Student-Athlete Career Situation Inventory (SACSI; Cox et al., 2009).

Your involvement in this project will be kept as confidential as legally possible. All data will be reported in the aggregate. I will not ask any information that should lead back to your identity as a participant. Your participation is completely voluntary. You may skip any question that you do not wish to answer and you may discontinue at any time.

I thank you in advanced for you participation in this project, as it could be beneficial in understanding college student-athlete career development. Should you have any interests in participation or questions regarding this research study, please contact Adrian Ferrera at (304) 293-2221 or by email at Adrian.Ferrera@mail.wvu.edu .

Thank you for your time and help with this study.

Sincerely,

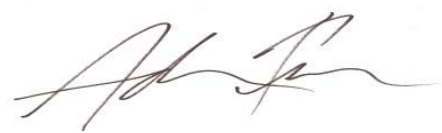

Adrian Ferrera, EdM

West Virginia University

Sport and Exercise Psychology

Doctoral Student 


\section{Appendix B}

Student-Athlete Demographics Questionnaire

1. What is your current age in years?

2. Which ethnic group do you most identify with? (please check one)
a. African-American/Black
b. Asian American/Asian
c. Caucasian
d. Hispanic/Latino
e. Native American
f. Other (please specify):

3. What is your current academic standing?
a. Freshman
b. Sophomore
c. Junior
d. Senior
e. Fifth-year senior
f. Graduate

4. What is your current overall GPA?
a. $>3.5$
b. 3.01 to 3.5
c. 2.51 to 3.0
d. 2.0 to 2.5
e. $<2.0$

5. What sport(s) do you participate in as a varsity collegiate athlete at your university?

6. Have you had any work or internship experience that relates to your academic major or a future career that is NOT related to playing a professional sport?

$$
\text { Yes _ No }
$$

If so, describe in as much detail as possible:

7. Do you have an expectation to compete in your sport at the professional level? 
Yes __ No

8. Have you ever used the universities Career Services Center before?

Yes _ No No

If so, please describe the manner in which you used it.

9. Would you be interested in being a part of a group discussion to share ideas of how to better assist student student-athletes with their career development needs? If so, please provide an email address where you can be reached.

Phone Number:

Email address: 


\section{Appendix C}

Student-Athlete Career Situation Inventory-Revised Male (SACSI-RM)

INSTRUCTIONS: Please CIRCLE the number that corresponds with the extent to which you agree or disagree with each item.

\begin{tabular}{|c|c|c|c|c|}
\hline 1 & 2 & 3 & 4 & 5 \\
Strongly Disagree & Disagree & Neutral & Agree & Strongly Agree \\
SD & D & N & A & SA \\
\hline
\end{tabular}

1. I do not have enough time to explore potential career opportunities.

$\begin{array}{ccccc}\text { SD } & \mathbf{D} & \mathbf{N} & \mathbf{A} & \mathbf{S A} \\ 1 & 2 & 3 & 4 & 5 \\ 1 & 2 & 3 & 4 & 5 \\ 1 & 2 & 3 & 4 & 5 \\ & & & & \\ 1 & 2 & 3 & 4 & 5\end{array}$

2. I have enough career-related information to make informed decisions about potential careers.

3. I am confident about my ability to find a satisfactory career.

4. My athletic involvement limits me from exploring potential careers until my season is over.

5. I have a good understanding of the steps I need 1 to take to find a satisfactory career.

6. I have a strong interest in at least one potential

1

2

3
career.

7. I am often too tired to explore my career interests.

$\begin{array}{lllll}1 & 2 & 3 & 4 & 5\end{array}$

8. Excelling in academics is as important to me as $\quad \begin{array}{lllll}1 & 2 & 3 & 4 & 5\end{array}$ excelling in my sport.

9. I am an athlete first, student second.

$1 \quad 2 \quad 3 \quad 4 \quad 5$


10. Many job-related skills can be learned from experiences in sport.

11. I believe that being an athlete makes me more suitable for certain careers.

12. My main reason for being at this university is to participate in my sport.

13. My commitments as an athlete do not hinder me from exploring potential career opportunities.

14. The time I have spent being an athlete has kept me from doing other things that might help me explore possible careers.

15. Being an athlete has helped me develop skills that will help me be successful in my desired career.

16. Being an athlete has influenced my thinking about what I might want to do for a career.

17. In choosing a major, I am more concerned about what is easiest to manage with my athletic commitment than about what really interests me.

18. Most of the academic decisions I make are strongly influenced by what others may suggest.

19. I have a good sense of what interests me academically.

20. I am more concerned with just graduating, rather than the field in which I actually get my degree in.

21. I am happy with my current major.

22. I feel pressure from others to pursue a particular career. $\begin{array}{lllll}\text { SD } & \mathbf{D} & \mathbf{N} & \mathbf{A} & \text { SA }\end{array}$

$\begin{array}{lllll}1 & 2 & 3 & 4 & 5\end{array}$

$\begin{array}{lllll}1 & 2 & 3 & 4 & 5\end{array}$

$\begin{array}{lllll}1 & 2 & 3 & 4 & 5\end{array}$

$\begin{array}{lllll}1 & 2 & 3 & 4 & 5\end{array}$

$\begin{array}{lllll}1 & 2 & 3 & 4 & 5\end{array}$

$\begin{array}{lllll}1 & 2 & 3 & 4 & 5\end{array}$

$\begin{array}{lllll}1 & 2 & 3 & 4 & 5\end{array}$

$\begin{array}{lllll}1 & 2 & 3 & 4 & 5\end{array}$

$\begin{array}{lllll}1 & 2 & 3 & 4 & 5\end{array}$

$\begin{array}{lllll}1 & 2 & 3 & 4 & 5\end{array}$

$\begin{array}{lllll}1 & 2 & 3 & 4 & 5\end{array}$

$\begin{array}{lllll}1 & 2 & 3 & 4 & 5\end{array}$

$\begin{array}{lllll}1 & 2 & 3 & 4 & 5\end{array}$




\begin{tabular}{|c|c|c|c|c|}
\hline & SD & D & $\mathbf{N}$ & $\mathbf{A}$ \\
\hline $\begin{array}{l}\text { 23. I am pursuing a certain career only because } \\
\text { others have told me I would be good at it. }\end{array}$ & 1 & 2 & 3 & 4 \\
\hline $\begin{array}{l}\text { 4. I am focusing more on preparing for a career } \\
\text { han on becoming a professional athlete. }\end{array}$ & 1 & 2 & 3 & 4 \\
\hline $\begin{array}{l}\text { 25. Because I am an athlete, I have a mental edge } \\
\text { hat others might not have. }\end{array}$ & 1 & 2 & 3 & 4 \\
\hline
\end{tabular}




\section{Appendix D}

Student-Athlete Career Situation Inventory Revised - Female (SACSI-RF)

INSTRUCTIONS: Please CIRCLE the number that corresponds with the extent to which you agree or disagree with each item.

\begin{tabular}{|c|c|c|c|c|}
\hline 1 & 2 & 3 & 4 & 5 \\
Strongly Disagree & Disagree & Neutral & Agree & Strongly Agree \\
SD & D & N & A & SA \\
\hline
\end{tabular}

1. I do not have enough time to explore potential career opportunities.

2. I have enough career-related information to make informed decisions about potential careers.

3. I am confident about my ability to find a satisfactory career.

4. My athletic involvement limits me from exploring potential careers until my season is over.

5. I have a good understanding of the steps I need to take to find a satisfactory career.

6. I am often too tired to explore my career interests.

7. Excelling in academics is as important to me as excelling in my sport.

8. I am an athlete first, student second.
SD $\quad$ D $\quad$ N $\quad$ A $\quad$ SA

$\begin{array}{lllll}1 & 2 & 3 & 4 & 5\end{array}$

$\begin{array}{lllll}1 & 2 & 3 & 4 & 5\end{array}$

$\begin{array}{lllll}1 & 2 & 3 & 4 & 5\end{array}$

$\begin{array}{lllll}1 & 2 & 3 & 4 & 5\end{array}$

$\begin{array}{lllll}1 & 2 & 3 & 4 & 5\end{array}$

$\begin{array}{lllll}1 & 2 & 3 & 4 & 5\end{array}$

$\begin{array}{lllll}1 & 2 & 3 & 4 & 5\end{array}$

$\begin{array}{lllll}1 & 2 & 3 & 4 & 5\end{array}$


9. Many job-related skills can be learned from experiences in sport.

\section{$\begin{array}{lllll}\text { SD } & \mathbf{D} & \mathbf{N} & \text { A } & \text { SA }\end{array}$}

$\begin{array}{lllll}1 & 2 & 3 & 4 & 5\end{array}$

$\begin{array}{lllll}1 & 2 & 3 & 4 & 5\end{array}$

10. I have many personal goals outside of sport.

11. I believe that being an athlete makes me more $\begin{array}{lllll}1 & 2 & 3 & 4 & 5\end{array}$ suitable for certain careers.

12. My main reason for being at this university is to participate in my sport.

13. My commitments as an athlete do not hinder

$\begin{array}{lllll}1 & 2 & 3 & 4 & 5\end{array}$

me from exploring potential career opportunities.

14. The time I have spent being an athlete has kept me from doing other things that might help me explore possible careers.

15. Being an athlete has helped me develop skills that will help me be successful in my desired career.

16. Being an athlete has influenced my thinking about what I might want to do for a career.

17. In choosing a major, I am more concerned about what is easiest to manage with my athletic commitment than about what really interests me.

18. Being a professional athlete is the only career that interests me.

$\begin{array}{lllll}1 & 2 & 3 & 4 & 5\end{array}$

$\begin{array}{lllll}1 & 2 & 3 & 4 & 5\end{array}$

19. I have a good sense of what interests me academically.

$\begin{array}{lllll}1 & 2 & 3 & 4 & 5\end{array}$

20. I am more concerned with just graduating, rather than the field in which I actually get my

$\begin{array}{lllll}1 & 2 & 3 & 4 & 5\end{array}$
degree in. 


$\begin{array}{llllll} & \text { SD } & \text { D } & \text { N } & \text { A } & \text { SA } \\ \begin{array}{l}\text { 21. I am happy with my current major. } \\ \text { 22. I am focusing more on preparing for a career }\end{array} & 1 & 2 & 3 & 4 & 5 \\ \text { than on becoming a professional athlete. } & & & & & \\ \text { 23. Because I am an athlete, I have a mental edge } & 1 & 2 & 3 & 4 & 5\end{array}$
that others might not have. 


\section{Appendix E}

Attitudes Toward Career Counseling Scale

Below are statements pertaining to career counseling. Read each statement carefully and indicate the degree to which you agree or disagree by using the following scale:

\begin{tabular}{|c|c|c|c|c|c|}
\hline 1 & 2 & 3 & 4 & 5 & 6 \\
$\begin{array}{c}\text { Strongly } \\
\text { Disagree }\end{array}$ & Disagree & Mildly & Mildly Agree & Agree & $\begin{array}{c}\text { Strongly } \\
\text { Agree } \\
\text { SD }\end{array}$ \\
\hline
\end{tabular}

Please express your honest opinion in rating statements. There are no "wrong" answers and the only right ones are the ones you honestly feel or believe. It is important that you answer every item.

1. If a career related dilemma arose for me, I would be

SD D $\quad$ MD $\quad$ MA $\quad$ A $\quad$ SA pleased to know that career counseling services are available.

2. Career counseling can be an effective way to learn what $\quad \begin{array}{llllllll}1 & 2 & 3 & 4 & 5 & 6\end{array}$ occupation is best suited for my interests.

$\begin{array}{lllllllll}\text { 3. Career counseling is a valuable resource in making a career } & 1 & 2 & 3 & 4 & 5 & 6\end{array}$ choice.

4. If I was in a career transition, I would value the

$\begin{array}{llllll}1 & 2 & 3 & 4 & 5 & 6\end{array}$ opportunity to see a career counselor.

5. If I were having trouble choosing a major, I would not hesitate to schedule an appointment with a career counselor.

6. I could easily imagine how career counseling could be beneficial for me.

7. Working with a trained career counselor might be a helpful $\quad \begin{array}{lllllll}1 & 2 & 3 & 4 & 5 & 6\end{array}$ way to feel more confident about career decisions.

8. With so many different ways to get help on career related $\quad \begin{array}{llllllll}1 & 2 & 3 & 4 & 5 & 6\end{array}$ decisions, I see career counseling as a relatively important.

9. I fear the negative stigma associated with seeing a career $\quad \begin{array}{llllllll}1 & 2 & 3 & 4 & 5 & 6\end{array}$ counselor.

10. Talking to a therapist regarding career issues is a sign of $\quad \begin{array}{llllllll}1 & 2 & 3 & 4 & 5 & 6\end{array}$ weakness. 
SD D MD MA A SA

11. My feelings about counseling in general would make me hesitant to see a career counselor.

12. If I was seeing a career counselor, I would not want anyone to know about it.

13. Seeing a career counselor to discuss career issues is a very private matter that should not be discussed with anyone.

14. Having to see a counselor to talk about career related concerns is a sign of indecisiveness.

15. I would be too embarrassed to ever schedule an appointment with a career counselor.

16. In all likelihood, a career counseling experience for me would be quite depressing. $\begin{array}{llllll}1 & 2 & 3 & 4 & 5 & 6\end{array}$

$\begin{array}{llllll}1 & 2 & 3 & 4 & 5 & 6\end{array}$

$\begin{array}{llllll}1 & 2 & 3 & 4 & 5 & 6\end{array}$

$\begin{array}{llllll}1 & 2 & 3 & 4 & 5 & 6\end{array}$

$\begin{array}{llllll}1 & 2 & 3 & 4 & 5 & 6\end{array}$

$\begin{array}{llllll}1 & 2 & 3 & 4 & 5 & 6\end{array}$ 


\section{Appendix F}

Student Demographic Questionnaire

1. What is your current age in years?

2. Which ethnic group do you most identify with? (please check one)
a. African-American/Black
b. Asian American/Asian
c. Caucasian
d. Hispanic/Latino
e. Native American
f. Other (please specify):

3. What is your current academic standing?
a. Freshman
b. Sophomore
c. Junior
d. Senior
e. Fifth-year senior
f. Graduate

4. What is your current overall GPA?
a. $>3.5$
b. 3.01 to 3.5
c. 2.51 to 3.0
d. 2.0 to 2.5
e. $<2.0$

5. Have you had any work or internship experience that relates to your academic major or a future career?

$$
\text { Yes _ No }
$$

If so, describe in as much detail as possible: 
6. Have you ever used the universities Career Services Center before?

Yes __ No _ _

If so, please describe the manner in which you used it. 


\section{Appendix G}

Athletic Identity Measurement Scale (AIMS)

Please circle the number that best reflects that extent to which you agree or disagree with each statement regarding your sport participation.

1. I consider myself an athlete.

$\begin{array}{lllllllll}\begin{array}{l}\text { Strongly } \\ \text { Disagree }\end{array} & 1 & 2 & 3 & 4 & 5 & 6 & 7 & \begin{array}{c}\text { Strongly } \\ \text { Agree }\end{array}\end{array}$

2. I have many goals related to sport.

$\begin{array}{lllllllll}\begin{array}{l}\text { Strongly } \\ \text { Disagree }\end{array} & 1 & 2 & 3 & 4 & 5 & 6 & 7 & \begin{array}{l}\text { Strongly } \\ \text { Agree }\end{array}\end{array}$

3. Most of my friends are athletes.

$\begin{array}{lllllllll}\begin{array}{l}\text { Strongly } \\ \text { Disagree }\end{array} & 1 & 2 & 3 & 4 & 5 & 6 & 7 & \begin{array}{l}\text { Strongly } \\ \text { Agree }\end{array}\end{array}$

4. Sport is the most important part of my life.

$\begin{array}{lllllllll}\begin{array}{l}\text { Strongly } \\ \text { Disagree }\end{array} & 1 & 2 & 3 & 4 & 5 & 6 & 7 & \begin{array}{c}\text { Strongly } \\ \text { Agree }\end{array}\end{array}$

5. I spend more time thinking about sport than anything else.

$\begin{array}{lllllllll}\begin{array}{l}\text { Strongly } \\ \text { Disagree }\end{array} & 1 & 2 & 3 & 4 & 5 & 6 & 7 & \begin{array}{l}\text { Strongly } \\ \text { Agree }\end{array}\end{array}$

6. I feel bad about myself when I do poorly in sport.

$\begin{array}{lllllllll}\begin{array}{l}\text { Strongly } \\ \text { Disagree }\end{array} & 1 & 2 & 3 & 4 & 5 & 6 & 7 & \begin{array}{l}\text { Strongly } \\ \text { Agree }\end{array}\end{array}$

7. I would be very depressed if I were injured and could not compete in sport.

$\begin{array}{lllllllll}\text { Strongly } & 1 & 2 & 3 & 4 & 5 & 6 & 7 & \begin{array}{l}\text { Strongly } \\ \text { Disagree }\end{array} \\ & & & & & & & & \text { Agree }\end{array}$




\section{Appendix H}

\section{Career Locus of Control Scale (CLCS)}

Directions: For each of the following, indicate whether you consider it True (T) or False (F) for you.

1. Getting a good job is primarily a matter of being in the right place at the right time. ${ }^{*} \quad \mathrm{~T} \quad \mathrm{~F}$

2. I expect that I will be able to get a career-entry job within a month after I start looking $\quad \mathrm{T} \quad \mathrm{F}$ for one without much difficulty.

3. College grades play a very large role in getting a job.

4. I expect that my social/family/college connections will be the primary factor in getting $\quad \mathrm{T} \quad \mathrm{F}$ my first job. *

5. I expect to get a job primarily on my record of hard work.

6. I expect that when I go for a job interview, whether I am successful or not will largely depend on the impression the interviewer makes of me: there is little I can do to anticipate how the interviewer will perceive me. *

7. I am confident that the placement services on campus will be able to find me an $\quad \mathrm{T} \quad \mathrm{F}$ excellent job upon graduation. *

8. I would take a low paying position upon graduation that would help me in my career $\quad \mathrm{T} \quad \mathrm{F}$ over a higher paying job that was not related to my career objectives.

9. I expect to be hired for my first job out of college on the basis of the skills I have $\quad \mathrm{T} \quad \mathrm{F}$ worked on developing.

10. One day I will just happen onto a career option that is right for me. * $\quad$ T F

11. I believe that the right career will just come my way. * $\quad \mathrm{T} \quad \mathrm{F}$

12. There are too many factors involved in getting a job or entering a career that you have $\quad T \quad F$ no control over to worry about it. *

13. There is too much emphasis on getting a job these days in college. $\quad \mathrm{T} \quad \mathrm{F}$

14. Senior year is the time to start worrying about selecting a career. $\quad$ T $\quad F$

15. I am very committed to my career, and I will do what I need to succeed in it. $\quad$ T F

16. Most of the people I know have just "lucked" into a career that was right for them. * $\quad \mathrm{T} \quad \mathrm{F}$

17. I have only a vague idea of what I want to be doing five years after graduation. $\quad \mathrm{T} \quad \mathrm{F}$

18. I hate to think about careers and life after school. $\quad \mathrm{T} \quad \mathrm{F}$

\section{* denotes external statements}




\section{Appendix I}

\section{Extended Review of Literature}

The collegiate athletic careers of student-athletes eventually come to an end for one of several reasons: completed eligibility, injury, being cut from the team, or personal decisions (Taylor \& Ogilvie, 1994). Approximately $2 \%$ of college student-athletes will continue on to compete at the professional level (NCAA, 2012b), while leaving the other $98 \%$ to discover and pursue other career paths. While most students attend college in preparation for a career upon graduation, student-athletes can prepare for both a career as a professional athlete or another occupation. In the event that a professional athletic career is not realistic, possible or desired, are student-athletes prepared to pursue a non-athletic career following their tenure as a collegiate athlete? Although the National Collegiate Athletic Association (NCAA, 2010) has pushed for higher graduation rates, does this percentage matter if student-athletes are not ready to enter the "real world?" To answer this question we must understand student-athletes, their athletic and academic environments, factors that influence their career decisions, the career development process, and ultimately the student-athlete career situation.

\section{Student-Athlete Career Situation}

The concept student-athlete career situation refers to the development and preparation of career attitudes, beliefs, and interests of college student-athletes (Sandstedt, Cox, Martens, Ward, Webber, 2004). This concept was derived over time from career development theories. Super (1957a) was one of the first to introduce his theory of career development (formerly vocational development) as it derived from the literature in vocational choice. Rather than the concept of "choice" being viewed as an event, Super (1957a) proposed it as a process including a series of decisions which help individuals to determine their occupation. As decisions are made, one's 
career development moves along a continuum which begins in early childhood and ends later in life. Similar to other forms of development (e.g., emotional and social), Super (1957a) broke down this continuum into vocational stages of a person's life, with each stage defined by specified characteristics and behaviors. For example, during the exploration stage (age 15-24) one should try new roles and explore occupations through leisure activities and part-time work (Super, 1957b). To denote the degree of development attained or the point reached on the continuum, the term "vocational maturity" was used (Super, 1957a). Super, Crites, Hummel, Moser, Overstreet, and Warnath (1957b) defined vocational maturity in two ways: by one's actual life stages in relation to expected life stages and by how one handles the appropriate developmental tasks. These definitions led to the possibility of being vocationally mature by one standard, but not the other. This ambiguity of definitions led Crites (1961) to define vocational maturity by the completion of developmental tasks and behaviors that should occur within each expected life stage.

Even though it may be challenging, when student-athletes enter college they too should complete the developmental and behavioral tasks established by Super (1957a). Being that college student-athletes are a specific population, the term career situation is often used to determine their career development (Sandstedt et al., 2004). To measure one's career situation, these researchers created the Student-Athlete Career Situation Inventory (SACSI) since there was no inventory designed specifically with student-athletes in mind. Sandstedt and colleagues concluded that there were five factors (i.e. barriers to career development, career development self-efficacy, career versus sport identity, locus of control, and sport to work relationship) that contributed to a student-athlete's career situation. The SASCI has since been revised and two gender specific versions have been created (Cox, Sadberry, McGuire, \& McBride, 2009). The 
factors for the revised SASCI are career confidence, low career interest, academic/career important, sport facilitates, barriers, and sport identity. The factor career confidence represents a student-athlete's belief in their ability to complete career development tasks. The factor low career interest reflects a perception that academics and a future career are not a priority while the factor academic/career important indicates that academics and a career are just as important as athletics. The factor sport facilitates denotes the student-athletes' ability to recognize that certain sport skills can be transferable into a career setting. The factor barriers represents aspects of the student-athlete role that can hinder career development and the factor sport identity represents student-athlete's view of self as being focused more on athletics rather than academics and career achievements. The following sections will provide details of the literature as it relates to each factor of the revised SASCI.

Barriers. Sandstedt and associates (2004) proposed that any inherent aspect of a studentathlete's life that hinders career development is considered a barrier. Life as a student-athlete can present several career development barriers. According to Watt and Moore (2001) a college student-athlete is a student who plays a sport(s) at the intercollegiate level. They engage in activities similar to those of traditional college students (e.g. attending classes, studying, campus activities), but student-athletes add practices, weight training sessions, travel to competitions, and other athletic-affiliated events to their schedules, hence adding to the complexity of their student role (Watt \& Moore, 2001). Having these athletic commitments can prevent studentathletes from attending events that could foster their career development. For example, if there is a career fair during the day, a student-athlete's day may contain weight lifting in the morning, followed by class, another class, study hall, practice, and more study hall. This only leaves enough time between each obligation for food, getting to and from the next commitment, and 
extremely limited time for career related, social or other activities. Their lifestyle is dictated by their sport and days can be preset to ensure they meet necessary requirements.

Other barriers could involve regulations and requirements set forth by the NCAA. Student-athletes are expected to meet academic requirements set forth by the NCAA. Academic Progress Rate (APR) is one measure used by the NCAA to determine the academic performance of student-athletes from term to term (NCAA, 2010). This score is based on team members' academic performance. For the 2012-2013 academic year, each team must obtain a minimum 900 APR score for a four-year period or average a 930 APR in their two most recent years (NCAA, 2010). These requirements need to be met for the team to be eligible for competition. Individual student-athletes must also maintain a specified grade point average (GPA) to remain eligible for competition (Pinkney \& Tebbe, 2009). With these types of academic requirements in place, some are concerned that student-athletes and coaches will respond by lowering their academic standards and/or enrolling in "meaningless degree" programs as a means of meeting required scores to remain eligible for competition (Knight Commission, 2001). It is of further concern that student-athletes may decide on a major (or have one decided for them) because the required courses will not conflict very much with their athletic schedules. This scenario is a perfect example of one of the career-related decisions student-athletes may face. In essence, student athletes may need to consider choosing a major that does not prepare them for a desirable future career, where the classes are unlikely to interfere with their athletic schedules. In these situations, student-athletes must assess and evaluate their circumstances to determine what is best for their future. As student-athletes balance athletics and academics, possible barriers to their career development might include: time constraints, athletic commitments, knowledge of resources or limited resources. 
Career confidence. Having confidence in one's ability to make career decisions is an essential component of career development. Sandstedt and colleagues (2004) refer to studentathletes' confidence in their ability to engage in career development tasks as career development self-efficacy. Bandura (1977) was the first to introduce the concept of self-efficacy. The foundation of this concept is based on outcome expectancy (i.e. believing certain behaviors will lead to specific outcomes) and efficacy expectations (i.e. belief that one can successfully execute the behavior required to produce the outcome). Ultimately, efficacy expectations influence choices of behaviors and effort expended to complete a task. If perceived self-efficacy of a task is not strong, situations and settings that pose a threat to an individual will be avoided or the appropriate amount of effort to successfully complete a task will not be given. Taylor and Betz's (1983) applied Bandura's (1977) self-efficacy theory to career development and introduced the term career decision self-efficacy.

Career decision self-efficacy is defined as having the belief in one's ability to successfully complete career-related tasks. Cox and colleagues' (2009) revision of the SACSI led to the renaming of the career development self-efficacy factor to career confidence. Studentathletes with high career confidence believe they have the ability to successfully complete necessary career-related tasks (e.g. choosing a major, seeking career advice, networking with employers at career fairs). Therefore, if student-athletes are provided with the knowledge and skills of how to pursue a career, career development tasks should not be seen as a threat leading student-athletes to exert more effort towards them.

Sport identity and Academic/career important. Student-athletes can potentially view themselves as students with athletic abilities who focus on academics or as athletes fixated on athletic achievements. Seeing oneself more as a student pursuing academic and career 
achievements rather than athletic achievements was previously described by the factor career verses sport identity (Sandstedt et al., 2004). Now the same concept is expressed only for male student-athletes in the revised factor academic/career important (Cox et al., 2009). For females, the revised factor sport identity indicates that student-athletes are more focused on athletic endeavors than academic and career related issues (Cox et al. 2009). This is similar to a studentathlete with a high athletic identity, which is defined as the degree to which athletes identify with their athlete role (Brewer, Van Raalte, Linder, \& Darwyn, E., 1993).

According to Medalie (1981), college is a place where students begin to establish a sense of who they are in the world as they move closer to adulthood. Student-athletes have the opportunity to establish themselves as students, athletes, or both. Because student-athletes must decide how much attention to give to either role and are also subjected to pressures to excel in each, this environment could provide student-athletes with an uncertain sense of who they are or who they will become.

Although identities are further developed during the college years, it is also possible for a student (or student-athlete) to enter college with a foreclosed identity (Marcia, 1966; Medalie, 1981) (i.e. committing to a path without enough information or exploration). For example, student-athletes may commit to a career path (e.g. professional athlete, doctor, lawyer) without much information or direction, and dedicate their time and energy toward that profession only to later realize it is not what he/she expected or desired, or to find it to be unattainable. These results could force a student-athlete to start over, change majors or pursue a new career path. When making these changes, student-athletes must consider NCAA eligibility requirements as to not jeopardize their athletic eligibility. These restrictions make it harder for student-athletes to change their career plans should their interests or identity shift during their tenure in college. 
Nonetheless, student-athletes have options of which role they choose to identify with and this choice will influence their career development.

Lack of career interest. The regulated lifestyle of student-athletes can limit their control over the decisions they make. Seeing that career development is a series of decisions and choices, the student-athlete's view of these choices must be considered. The revised factor lack of career interest represents student-athletes lack of given attention to actively pursue or engage in career related tasks (Cox et al., 2009). This is similar to the factor locus of control which is defined by the degree to which student-athletes believe they have power over their career decisions (Sandstedt et al., 2004). Holding the view that their actions can determine their future outcomes is an internal locus of control (Trice, Haire, \& Elliot, 1989). Believing their actions have no bearing on their future is considered an external locus of control (Trice et al., 1989). Once student-athletes arrive on campus they are told by athletic personnel what classes to take, where to go, and what time to be there. Their lives are dictated by a schedule focused on their sport. This type of lifestyle can create an environment that illustrates to student-athletes that they have no control over their future (external locus of control). Alternatively, student-athletes may believe that they can create opportunities for themselves by making decisions to attend events (e.g. career seminars, resume workshops, and career fairs) that can better prepare them for their future (internal locus of control). Since student-athletes can either possess an internal or external locus of control regarding career-related issues, administrators need to understand student-athlete locus of control to create the necessary environment or programs to aid in the overall career development of student-athletes.

Sport facilitates. There are some behaviors and characteristics that are learned in sport that can be used within a career setting (e.g. leadership, goal setting, handling pressure situation, 
time management). Recognizing the transferability of these skills defines the factor sport to work relationship (Sandstedt et al., 2004). Cox and colleagues (2009) later established the variable sport facilitates as it was concluded that certain skills acquired in sport could promote confidence in a career. For example, if the quarterback of a football team and a project manager of an engineering team were to compare skills they use in their respective environments, some similarities would be found. Both would probably have the ability to lead, direct, and manage multiple people in their team. They are probably expected to meet the expectations set by a higher authority. Most likely both will be held responsible for the successes and failures of their respective teams. These examples illustrate how parallel skills can be learned or cultivated by athletic participation and can contribute to careers in the working world. Even though athletics can be considered a barrier, athletics can also add to student-athletes career situations.

The literature presented above illustrates the complexity of the student-athlete career situation. It is clear that there are several factors that influence a student-athlete's career situation. As student-athletes progress through college and learn more about themselves, they will continue to develop their beliefs and attitudes about their future and will have to make decisions. Since several factors are associated with the student-athlete career situation, the following literature will provide a theoretical foundation for the six factors (career confidence, low career interest, academic/career important, sport facilitates, barriers, and sport identity) regarding the student-athlete career situation, student-athletes' athletic and academic environments, the career development process, and research results related to student-athlete's career maturity.

\section{Career Development}


Sandstedt and colleagues' (2004) concept of the student-athlete career situation is built from the foundation of research conducted in the area of career development. Therefore, it is only appropriate that this topic be discussed in some depth. Super (1957a) and Crites (1961) were some of the first researchers to establish a career development framework. This and other theories will be presented in this section.

Super's career development theory. Super described career development as a continuous process involving the interaction of certain behaviors, vocational development tasks, role factors, personal factors, and situational factors (1957b) that take place during a person's life. Super believed that the career development process was another aspect of an individual's overall development and that it was similar to that of social, emotional, and intellectual development (Super, 1957a). With this belief, Super postulated that career development can be viewed on a continuum from early childhood to later life and that this continuum could also be broken down into stages across one's life (i.e. growth stage, exploration stage, establishment stage, maintenance stage, and decline stage).

Super and colleagues (1957b) provided an outline that illustrated the career-related experiences that individuals may face during different stages of their lives. The growth stage, from birth to age 14, is a period when individuals develop their self-concept. Many ideals and beliefs are shaped by significant family members and the school environment. During the exploration stage (age 15 to 24), it is typical for individuals to examine who they are, try new roles, and engage in occupational exploration. If in college, individuals may take courses that match their interests or attend events like career fairs to begin discussions with professionals that share similar interests. Specifically, between the ages of $18-21$, more thought should be given to professional training or preparing for the work force. Seeking opportunities to observe 
professionals in their field, obtaining certifications, or attending specialized training courses are some examples of what students can do to prepare for their future careers. Between the ages of 22 and 24, individuals should select an appropriate field and have begin work within that field. This work can be in the form of internships, externships, or part-time employment. Within the establishment stage (ages 25-44), individuals should strive to find their place within their occupational field. It is not uncommon for people to shift from job to job early in their careers as this is considered a form of occupation trial and error. When they have found their place in the working world and are determined to continue in this role, they have moved into the maintenance stage (ages $45-64$ ). Finally, the decline stage is a period starting at about age 65, where physical and mental abilities wane, work activity decreases, and new roles develop.

The aforementioned stages and their behaviors construct Super's career development continuum. Super used this continuum as a measurement of one's career development, and the term career maturity (formerly vocational maturity) is used to determine the degree of development along this continuum (Super, 1957a).

Crites' model of career development. Crites (1961) proposed that career maturity should be defined by behaviors and tasks and measured with an age and point scale. Because vocational behaviors mature with age, Crites (1976) formulated his model of career development based on the decisions, adjustments, and behaviors that occur during early adulthood. Crites believed people transition from school to the workforce between the ages of 16 and 25 . According to Super's (1957) career development continuum, this period extends from the Exploration stage into the Establishment stage.

Crites (1976) also believed that as individuals move through life, it is almost inevitable that they will face some career opposition. This opposition could come from internal or external 
factors that prevent career success and force them to adapt or succumb to the circumstances of the situations. Those who can overcome these obstacles reach career satisfaction (i.e. are more career adjusted), while those who do not are considered less career adjusted. One overcomes these obstacles by making the appropriate career decisions (i.e. seeking assistance, guidance, learning from past situation). It is important to note that these decisions can be influenced by a number of factors (e.g. cultural, sociological, psychological, parental attitudes, and socioeconomic status). Whether individuals progress or remain stagnant along the career development continuum depends on their ability to adjust to presented circumstances.

\section{College Student Development}

The exploration stage (age 15 -24) of Super's career development continuum coincides with the ages that many students enter college. Since this is an important stage of career development, it is critical to understand the overall development of college students during this time. Chickering (1967) investigated college student development by reviewing Goddard College student records to determine if there were any changes in students while they were attending college, and if so, when did such changes take place. Faculty members at Goddard College established criteria to determine what it means to be an independent and purposeful student and the following six variables were established: 1) goal directedness, 2) personal stability and integration, 3) venturesomeness, 4) resourcefulness and organization, 5) full involvement, motivation and persistence, and 6) interdependence. The variable goal directedness was characterized as having somewhat well-defined meaningful goals in addition to an increasing ability to identify the relationship between purpose and other aspects of work life. The variable personal stability and integration described students who not only knew their strengths and weaknesses, but also knew what they wanted to become. Venturesomeness was 
characterized as having a willingness to confront problems and ask questions in order to discover new possibilities while pursuing autonomy, while the variable resourcefulness and organization described a student's awareness of resources (i.e. necessity and location) in addition to the efficiency and effectiveness in using such resources. The variable full involvement, motivation, and persistence described students who were willing to take on routine or difficult tasks and sustain effort when distractions are presented. The variable interdependence described students who understood that they are a part of a larger working network.

Following Chickering, Medalie (1981) expanded the literature on college student development by developing a year-to-year life cycle for the undergraduate experience as students create a bridge from childhood to adulthood during college. The cycle begins with divestment and investment in the freshman year, consolidation and choice during sophomore year, mastery and commitment during the junior year, and concludes with anticipating the world beyond during the senior year.

The works of Chickering (1967) and Medalie (1981) provide a foundation of knowledge outlining the process of college student development and their experiences. When students enter college, it is usually the beginning of a new life and students begin to define who they will become as adults. Students will select an academic major signifying a commitment toward a specified path. This decision is usually made after gathering information and exploring options. College student development is not completely linear as students may face opposition or lack motivation and direction at varying times. However, as they mature and have new experiences they learn more about themselves and what they want to do. This leads to making realistic plans toward their future and their career. While this is only a brief overview of college student 
development, the subsequent section will elaborate on college student development during each of the years of college.

Freshman year. During the first year of college, students are often trying to find out who they are. In the first semester, the variable venturesomeness had the highest mean score when compared to other variables (Chickering, 1967). This high score most likely occurs because students are in new surroundings, are trying to establish themselves in a new role and trying new things that they may have never been exposed to. While students engage in investigative behaviors in the first year of college, according to Super (1957b), similar characteristics are also displayed during the exploration stage of life. As for the variable personal stability and integration, a significant increase was found in mean scores of this variable from the first to second semester of the freshman year. This increase was seen as an indication that students gained a sense of their strengths and weaknesses and knew the kind of people they wanted to become.

In a similar manner to Super (1957b), Medalie (1981) described the first year of college as the divestment and investment years. This is a time when students sever relationships of the past and begin to invest in a new life. Part of this new life occurs with the selection of classes to prepare for future occupations even though students may have vague or unformulated interests. As students learn more about themselves, they are able to make better decisions in their following years.

Sophomore year. Within the second year of college, Medalie (1981) concluded that the primary overall task was to increase one's mastery of work while differentiating interest and making commitments to future goals. As Chickering (1967) broke down semesters, the venturesomeness mean scores dropped in the third semester but this drop was followed by a 
significant increase in the fourth semester. This change in venturesomeness scores might suggest that students begin to explore future career opportunities to help them develop personally and professionally prior to their final years of school. Furthermore, students were found to have had their highest levels of goal directedness during their fourth semester. An increase in these behaviors is perceived as rather important since it is usually required that students determine their academic major by the end of their sophomore year (Medalie, 1981).

The selection of a major can be a pivotal point that prompts students to seriously think about their futures. Those with foreclosed identities (i.e. deciding on a future path without exploring other options) must then determine if their intended career choice is reasonable or attainable. Although some students may be ready to make these decisions, this may provoke other students to experience feelings of apathy, alienation, or depression, and lead them to what is known as the "sophomore slump" (Medalie, 1981).

Junior year. The feelings and experiences (e.g. depression, alienation) during the sophomore slump can be forms of what Crites (1976) considered internal and external barriers during the career journey. However, those who surpass such opposition have the potential to achieve career satisfaction. Chickering (1967) described the period from the fourth to the fifth semester as the "fifth semester slump" (p. 300) since there were significant decreases in mean scores for the three variables "full involvement, motivation, and persistence" "resourcefulness and organization" and "interdependence" followed by an increase in later semesters, which is in accordance with expected behavior similar to that of the career development continuum. Medalie (1981) agreed that the middle of the junior year is a time when developmentally "on target" students begin to make progress toward the adult world as students may find summer 
work, have volunteer experiences related to their occupational interest or travel to experience life outside the academic world.

Senior year. Although the variable personal stability and integration had a significant increase from the first to second semester, this variable had another significant increase in mean scores from the sixth to the seventh semester (Chickering, 1967). When compared to their peers, purposeful and independent students had more balance and life perspective and knew what they wanted to be. Even though they may have encountered stressful periods during their life, their anxiety levels for academics, future occupation, family and marital status were rather low. Additionally, the variable full involvement, motivation and persistence increased steadily from the fifth to the seventh semesters. The characteristics of the two previously mentioned variables are in agreement with Super's (1957b) exploration stage and Crites' (1967) belief that vocational behaviors increase with age. These notions are further established with Medalie's (1981) conclusion that the senior year is the time to make realistic plans for the future.

Compared to entering college, future life and career decisions may not be easy to make, as Medalie (1981) suggests that there is no true structure to life after college. Upon entrance, four to five years of a person's life is structured with coursework and activities to prepare for or delay the inevitable. Since college is supposed to help individuals develop certain characteristics to aid them in their entrance into adulthood, upon departure it is hoped that students know what they want to be and have some motivation to fulfill their aspirations. Unfortunately, there are some students who may not fulfill developmental tasks while in college and therefore do not progress appropriately along the career development continuum. Therefore, it is important to identify these students and provide appropriate programs and assistance to ensure that career maturity is being developed. 


\section{Development of College Student-Athletes}

College student-athletes are one group that may not fulfill the developmental tasks described by Chickering (1967) and Medalie (1981). These tasks may not be fulfilled due to the pampered life-styles that they may become accustomed to after entering college. Studentathletes often have access to special living situations, study centers, and advisors who specifically work with and cater to them (Wittmer, Bostic, Phillips, and Waters, 1981). While these accommodations can be beneficial in stimulating academic success, this lifestyle may also include behaviors that lead to university athletic scandals, low student-athlete graduation rates, and the on-going process of maintaining athletic eligibility. So even though student-athletes may be students, they may not share the same experiences or environments as the average student.

The negative outcomes identified above prompted Wittmer and colleagues (1981) to create a course to help integrate all incoming student-athletes into college and improve their overall development. This course serves as another example of how student-athletes may receive specially adapted services to fit their needs. The key points emphasized in this course were selfconcept, vocational and academic awareness, leadership, racial relations, interpersonal communication skills and talking with the media. Previous research suggests that these are developmental skills that should be learned in the first years of college (Super, 1957b; Chickering, 1967; Medalie, 1981). For senior student-athletes, an exit-seminar was created to provide athletes with information that would immediately have an impact on their future upon graduation (i.e. buying a car, insurance, resume building, and job interviews). Prior to the implementation of these courses, it is possible that student-athletes may not have been provided with the necessary resources to ensure their progress along the career development continuum. 
After observing these deficiencies Wittmer and his colleagues suggested that appropriate measures should be taken to provide student-athletes with suitable career assistance.

Following the suggestions of Wittmer and colleagues (1981), Sowa and Gressard (1983) and Blann (1985) found developmental differences between student-athletes and their nonathlete counterparts using the Student Development Task Inventory (SDTI; Winston, Miller, \& Prince). The results indicated a significant difference between the two groups on the subscales of educational plans, career plans, and mature relationships with peers, with student-athletes scoring significantly lower than non-athletes on all three subscales (Sowa et al., 1983). However in comparison to non-athletes, underclass male athletes scored lower on educational and career planning (Blann, 1985). Furthermore, Division III athletes had significantly higher scores than Division I athletes with respect to both educational and career planning.

Sowa and Gressard (1983) indicated that education and career differences between student-athletes and student non-athletes could exist for a variety of biological and/or sociological reasons. Because athletes are often encouraged to engage in certain activities (e.g. team meetings, study hall, academic majors) by those in leadership positions (i.e. head/assistant coaches, athletic academic counselors, advisors), they may be unable to develop decision-making skills or may lack the ability to formulate their own educational and career goals. Another reason could be that some student-athletes' have aspirations to play at the professional level. Furthermore, student-athletes may have a harder time building independence and individuality because their lives are dictated by their athletic schedules. Dedicating extra time to one's sport may also limit time that could be used for career exploration activities. However, if studentathletes have intentions to play at the professional level, committing more time to their sport may appear to be most logical, even if that means neglecting academics. 


\section{Measuring Career Development and Other variables}

Several assessments have been designed to assess career development and other factors associated with career development. Newer inventories have been created to either address the limitations in previous inventories, investigate other variables associated with career development, and to provide the most reliable results for specific populations. This section will discuss these newer career development instruments and those which are associated with or influence career development.

Career Development Inventory. Career development is a continuous decision making process. Individuals must plan ahead and use appropriate resources to gather information which will aid them in making decisions. Their level of career maturity is based on their ability to make these decisions. Super (1973) intended to measure the career maturity of adolescents when he designed the Career Development Inventory (CDI) using the three subscales: 1) Planning Orientation, 2) Resources for explanation, and 3) Information and Decision-Making. The planning orientation scale was developed to determine a student's awareness of planning and choice. In this section, participants were asked to respond to 33 statements using one of the five provided responses. A sample statement was "Getting a part-time or summer job which will help me decide what kind of work I might go into." One of the possible responses was "I have not given any thought to this." The resources for explanation scale assessed the individual use of resources and the perceived availability of resources. This section contains 28 items of which are considered a source of information (e.g. Father or male guardian, college catalogue). The statement "I have gotten..." preceded the five answer choices (e.g. some useful information) that were provided so respondents could complete the response. The two previous subscales measured attitudinal factors, while the Information and Decision making Scale, a cognitive 
measure, assesses decision-making based on educational and occupational knowledge. A sample question would be "Which one of the following is the best source of information about job duties and opportunities?" There are 30 items in this section and each item has its own set of possible answers in which respondents must decide on the best possible answer. This is a paper-andpencil inventory with content that is acceptable for adolescents between the ages of 12 and 19 . The complete scores of individual students on the CDI could be compared with one another or compared against other students of the same gender, grade or age.

There is also a version of the CDI that is applicable to college and university level students. It is a 16-page booklet that contains 120 items appropriate for males and females (Savickas \& Hartung, 1996). This booklet has two parts: (I) career orientation and (II) Knowledge of preferred occupation. In the Career Orientation section, there are four scales that measure Career Planning (CP), Career Exploration (CE), Career Decision Making (DM), and World-of-Work information (WW). Part two measures Knowledge of Preferred Occupational group (PO). Each scale produces an individual score and the combination of subscales produces composite scores that represent Career Development Attitudes (CDA) (i.e. CP and CE), Career Development Knowledge (CDK) (i.e. DM and WW), and Career Orientation total (COT) (i.e. $\mathrm{CDA}$ and $\mathrm{CDK})$. High scores indicate that the test-taker can make choices and has appropriate attitudes and competencies to pursue career interests (Savickas \& Hartung, 1996). The CDI can be used to assess career maturity, evaluate and develop programs (only when appropriate), and individual counseling. Although the CDI has strong reliability and validity (Savickas \& Hartung, 1996), it is only designed to evaluate how adolescents cope with vocational development tasks (Super, 1973) 
Career Maturity Inventory. Varying slightly from the CDI (Super, 1973), Crites focused his assessment on the maturity of attitudes and competencies needed for practical decision-making (Hansen, 1974), which led to the development of the Career Maturity Inventory (CMI; Crites, 1973). This scale was comprised of both an attitude scale and a competencies test. The Attitude Scale assessed an individual's involvement in the career choice process, orientation toward work, independence in decision making, preference for career choice factors, and conception of the career choice process. This scale consisted of 50 statements which were derived from a pool of client statements made during vocational counseling sessions (Hansen, 1974). The statements required respondents to answer how each item applied to the world of work for them using "True" or "False" responses. A sample item would be "I seldom think about the job I want to enter" (Crites, 1973). Completion of this scale took 20 to 30 minutes (Hansen, 1974). Internal consistency (Kuder-Richardson Formula 20, KR-20) for the Attitude scale was established with a sample of sixth to twelfth graders with an average coefficient of .74. After one year, test-retest reliability was .71.

The competencies scale measured the following five cognitive variables: self-appraisal, knowledge of occupational information, selecting goals, planning ahead, and problem solving (Hansen, 1974). Each variable had 20 corresponding items which were written as hypothetical problems, plans, or jobs which were gathered from real life experiences, counseling case records, and biographies. Respondents were to respond to each item with what they believed to be the correct answer from the provided choices. A sample statement would be "Sandy is interested in becoming a dental hygienist. She must..." (Crites, 1973). The completion time for the CMI was approximately two hours and twenty minutes and provided the test taker with a profile containing a raw score and percentile rank for both scales. To be viewed as making progress 
along the career development continuum, an individual had to have a raw score in the $50^{\text {th }}$ percentile or higher. Those who scored below this standard were encouraged to seek guidance from teachers, parents, counselors and other trusted individuals. In 1978, the second edition of the Career Maturity Inventory was released. Internal consistency coefficients (KuderRichardson Formula [KR-20]) ranged from .50 to .72 with a median of .64 (Busacca and Taber, 2002). As for the competence test, median KR-20 coefficients for grades 9, 10, 11, and 12 were $.82, .86, .84$, and .84 , respectively (Busacca et al., 2002).

It was suggested that the CMI could be used to study problems in career development, assessing career programs and career education, determine the maturity of career attitudes and the service needs of students (Hansen, 1974). The reading level for the CMI ranged from sixth grade to senior level college students. Since the Attitude Scale and the Competence Test were not normed on national samples, generalizations were limited.

The CMI (Crites, 1973) was later revised to address concerns that developed over time (Crites \& Savickas, 1996). These revisions reduced completion time, made the CMI more applicable to other populations (i.e. younger and older individuals, males and females, and minority groups) and a career developer (CDR) was added, making the inventory more practical and less theoretical. Both the attitude and career competence test were reduced to 25 items each (i.e. 5 items for each of the previous subscale). Cross sectional and longitudinal data analyses were completed to identify items from the original CMI (Crites et al., 1973) that did not differentiate at the .01 level. Only items that met this criterion were kept for the revised version of the CMI (Crites et al., 1996). The response formats were also changed from "True" or "False" to "Agree" to "Disagree". Scores for the attitude scale ranged from 1 to 25 , and scores from the competence test also ranged from 1 to 25 , with high scores indicating a higher level of career 
maturity. The CDR was used to interpret each item which allowed the test taker to learn why a response would be mature or not. This learning experience increased knowledge of career decisions when retaking the CMI.

The reliability and validity of the attitude scale and competence test are reported as being similar to the second edition CMI (Crites et al., 1996). However, Busacca and Taber (2002) claimed that no psychometric data on the reliability and validity on the CMI-R have been published. Their analysis of the CMI-R were obtained with a convenience sample of 157 male and female ninth through twelfth grade students and Internal consistency reliabilities were .54, .52 , and .61 for the Attitude Scale, Competence Test, and total inventory score, respectively (Busacca et al., 2002).

My Vocational Situation. Previous inventories focused on the career maturity of respondents (Super, 1973; Crites, 1973), but did not include an identity component. Holland, Gottfredson, and Power (1980) expanded previous inventories with their investigation of identity and career decisions. They then defined vocational identity as having a clear sense of and stability in one's goals, interests, and talents. They concluded that having vocational identity led to self-confidence in one's ability to make good career decisions. To assess vocational identity, the inventory My Vocational Situation (MVS, Holland et al., 1980) was developed, and consisted of a vocational identity (VI) scale, an occupational information (OI) scale, and a barriers (B) scale. The CDI (Super, 1973) and CMI (Crites, 1973) did not contain identity or barriers scales.

The vocational identity scale consisted of 18 relevant statements where students responded with "True" or "False" for each statement as it pertained to them (Lucas, Gysbers, Buescher, \& Heppner, 1988). A sample statement from the vocational identity scale would be, 
"Making up my mind about a career has been a long and difficult problem for me" (Holland et al., 1980; p.1192). However, the occupational information scale began with the prompt, "I need the following information..." and was followed with statements about career information (e.g. how to find a job in my chosen career). This scale consisted of 4-items and required a "Yes" or "No" response (Lucas et al., 1988). The barriers scale also consisted of 4-items that required a "Yes" or "No" response, but the items did not have a preceding prompt similar to that of occupational information scale. A sample statement from the barriers scale would be "An influential person in my life does not approve of my vocation choice" (Holland et al., 1980).

Completion of the MVS produced three separate scores for vocational identity, occupational information, and barriers. The vocational identity score was based on the number of "False" responses provided to each statement. A high number of "False" responses (maximum 18) indicated a clear sense of identity, while a low number pointed to possible issues with making career decisions (Lucas et al., 1988). Scores for both the occupational information and barriers scales were produced by the number of "No" responses. High scores (maximum 4) indicated a limited need for occupational information and fewer perceived barriers to occupational goals (Lucas et al., 1988). Holland and colleagues (1980) concluded that an individual's inability to make good career decisions was due to either problems of vocational identity, lacking occupational information and/or appropriate training, or experiencing some environmental or personal barriers.

Construct validity for the MVS was established by administering it to 824 participants in high school, college, and business (Holland et al., 1980). The average age for this sample was 25.4 (males) and 23.0 (females) years old. Holland and colleagues (1980) described the construct validity of the vocational identity scale as "substantial" (p. 1198). They also regarded 
the occupational information scale and barriers scale as "useful checklists" (p. 1199) that can be used to help individuals identify their needs and problems. The KR-20 coefficient of the vocational identity scale, the occupational information scale and the barriers scales for male college students and workers was $.89, .79$, and .45 , respectively. The KR-20 coefficient of the vocational identity scale, occupational information scale and barriers scales for female college students and workers was $.88, .77$, and .65 , respectively.

Although the reliability of the occupational information scale and barriers scale are low, Holland and colleagues (1980) identified another construct, identity, which should be considered when investigating career development. Additionally, the MVS may not be a suitable inventory for student-athletes to complete, as they may have "clear and stable goals" of becoming a professional athlete, thus providing a false vocational identity.

Career Decision Self-Efficacy. Having self-confidence in one's ability to make good career decisions is described as career decision self-efficacy. Taylor and Betz (1983) measured confidence in making career decisions using the Career Decision Self-Efficacy Scale (CDSES). This 50-item scale was based on Crites' (1973) career competencies (i.e. self-appraisal, knowledge of occupational information, selecting goals, planning ahead and problem solving), which were tasks and behaviors deemed necessary for making career decisions. Each competency was developed into a subscale that included 10 items that were constructed to assess confidence to successfully complete each task. A sample item would be "Prepare a good resume" (Taylor et al, p. 66). Respondents were to rate their ability using a scale ranging from (0) No Confidence to (9) Complete Confidence. A total score for all 50 items could produce a maximum score of 450. Internal consistency for the entire scale was .97 (Betz, Klein, \& Taylor, 1996). Coefficient alphas for the subscales self-appraisal, occupational information, goal 
selection, planning and problem solving were $.88, .89, .87, .89$, and .86 , respectively (Taylor $\&$ Betz, 1983). The validity of the CDSES was determined by comparing it with the Career Decision Scale (CDS; Osipow et al., 1980). The CDS factors were moderately intercorrelated with the CDSES. Since this instrument was designed to assess self-efficacy in career related behaviors, from provided responses, areas in which a person may be lacking self-confidence could be determined and further interventions could be provided to assist the individual in those areas.

The CDSES has been used in several studies, but the length of the 50-item scale has raised concerns (Betz \& Talyor, 1996). It was determined that the 50-item measure was not ideal for research purposes, assessment in career counseling interventions, or program evaluations, and a shorter version was created (CDSE-SF; Betz et al., 1996). The CDSE-SF is a 25-item scale with five subscales: 1) self-appraisal, 2) occupational information, 3) goal selection, 4) planning and 5) problem solving. Each subscale consisted of 5-items. Respondents were to rate their ability using a scale ranging from (1) No Confidence at all to (10) Complete Confidence. The maximum score for the CDSE-SF is 250, while the minimum score is 25. Scores for each subscale ranged from 5 to 50 . Lower scores indicated a lack of confidence in one's ability to complete career decision tasks. Coefficient alphas for the subscales were self-appraisal, occupational information, goal selection, planning, and problem solving .73, .78, .83, .81, and .75 , respectively. Concurrent validity was established by comparing the 25-item CDSE-SF and the 50-item CDSES, among 184 students (81 males, 103 females) enrolled in an undergraduate introductory psychology course. The results revealed that the coefficient alphas for the 25-item CDSE-SF $(\alpha=.94)$ were nearly as high as the 50-item CDSES $(\alpha=.97)$. 
The revisions to the CDSE-SF improved usability for research and intervention purposes. Betz and colleagues (1996) believed the CDSE-SF could be used for program evaluations (e.g. pretest and posttest administration) and for counseling since it is short and could provide a framework of where the client is in their career decision making process.

Career Locus of Control Scale. Although people may have confidence in their ability to make decisions, this does not necessarily mean they believe that they perceive themselves to have control over making those decisions. The rationale used by individuals to determine why actions occur can be described as internal locus of control and external locus of control. Having the view that outcomes are dependent on one's own actions is an internal locus of control. Believing that outcomes are influenced by the task difficulty, powerful others, or chance is defined as having an external locus of control. To measure an individual's locus of control for career decisions, Trice, Haire, and Elliot (1989) developed the 18-item, Career Locus of Control Scale (CLCS). Respondents were to identify if the presented statements were "True" or "False" for themselves. Sample external statements from the CLCS include: "Getting a good job is primarily a matter of being in the right place at the right time." and "I believe the right career will just come my way". A total score (i.e. 0 to 8 ) was produced by calculating the total number of external responses and higher scores on this measure indicated more of an external focus, meaning the respondents believed their career development is out of their control.

The 18-item CLCS was derived from an initial 40-item research scale that was administered to two groups (Trice et al., 1989). One group was a sample of 50 sophomores and juniors at a private women's college and the other was a sample of 50 second-year male students enrolled in A.A. programs at a community college. In addition to the 40-item scale, the women's sample completed Rotter's (1966) I-E scale, a measure of locus of control was found, while the 
males completed the Crowne and Marlowe Social Desirability scale (1964). A significant correlation for the CLCS and Rotter's (1966) I-E scale was found $(.52, p<.01)$ indicating that the CLCS measures locus of control. A nonsignificant correlation was found with the male sample indicating that CLCS is not heavily influenced by social desirability $(-.13, \mathrm{p}>.10)$. KR20 for the women's and men's sample were .89 and .84 , respectively. Three weeks later, 41 men from the male sample completed the CLCS again, revealing a test-retest reliability coefficient of .93.

Trice, Haire, and Elliot (1989) also conducted other validity studies using the CLCS. A sample of 68 graduating seniors from a women's liberal arts college completed the CLCS. This sample was separated into three groups. Group 1 consisted of 28 students who received at least one job offer. Group 2 consisted of 21 students who applied for at least one job, but had not received an offer. Group 3 consisted of 19 students who had not applied for any jobs. Results indicated that a negative correlation existed with career locus of control and the number of submitted job applications. Those with fewer submitted applications had a higher external locus of control. In the second validity study it was believed that students with an external career locus of control would have difficulty deciding an academic major. A sample of 191 college juniors who yet to declare a major were asked to complete the CLCS and meet with their academic advisor. Following the meeting, students declared a major, declared a nonmajor curriculum, were referred to a group career counseling program, or were referred to individual counseling. The results indicated that there was a significant difference between groups that declared majors and those who were referred to counseling. Students who were referred to counseling had a higher level of career locus of control. 
Knowing an individual's locus of control can help understand the amount of energy that will be given when applying for jobs and selecting a major. Having this information can be useful in preparation, intervention, and identification of students who may be at risk for career development problems.

Athletic Identity Measurement Scale. It has been established that an individual's identity and their locus of control can influence their career decisions (Holland et al, 1980; Trice et al., 1989). For the student-athlete, their athletic environments can shape their beliefs of control and views of themselves. Although student-athletes may not have much control over their athletic situation, they can determine how much they choose to identify with their athlete or student roles. The degree to which individuals identify with their athlete role is considered their athletic identity (Brewer, Van Raalte, and Linder, 1993). Brewer and colleagues (1993) constructed a 10-item scale known as the Athletic Identity Measurement Scale (AIMS) to measure the affective, social, and cognitive aspects of athletes' identity. Participants were to respond to statements regarding their identity as they relate to athletic participation on a Likerttype scale with anchors Strongly Agree (7) to Strongly Disagree (1). Higher scores indicated a greater identification with an athlete role. Sample statements were "I spend more time thinking about sport than anything else" and "Sport is the only important thing in my life."

Construct validity for the AIMS was determined by comparing it with the Perceived Importance Profile (PIP; Fox, 1987) which is used to determine the importance of physical activity to college students. The AIMS (Brewer et al., 1993) and the PIP (Fox, 1987) were administered to 234 male and female students in undergraduate introductory psychology and sport psychology courses. A significant correlation $(r=.83)$ was found between the AIMS and the factor "importance of sports competence" on the PIP. Weak but significant correlations were 
also found between the AIMS and three PIP factors 1) importance of physical conditioning $(r=$ $.56, p<.0005), 2)$ importance of attractive body $(\mathrm{r}=.35, \mathrm{p}<.0005)$ and 3$)$ importance of physical strength" $(r=.53, p<.0005)$. Internal consistency was found as the AIMS had a coefficient alpha of .93. After a 14-day period, the test-retest reliability coefficient for the AIMS was .89, indicating that the measure is stable. The AIMS, the PIP, and the Physical Self-Perception Profile (PSPP; Fox \& Corbin) were also given to 90 members of a Division II college football team (Brewer et al., 1993). The internal consistency of the AIMS was found to be .81 .

This construct of athlete identity was developed from theories of self-concept. Selfconcept is built on one's judgment of their worth and competence in certain situations. An individual's view of self ultimately determines their self-esteem, affect, and motivation toward future behaviors. Brewer and colleagues (1993) rationalized that athletes with a strong athletic identity assign a great deal of importance to athletic or exercise endeavors, which can possibly have a positive effect on athletic performance. However, having a strong athletic identity can limit exposure to other activities and present difficulties as athletes make career transitions.

Student-Athlete Career Situation Inventory. Several career related inventories have been developed to examine specific aspects that influence career development (e.g. attitudes, self-efficacy, decision making, identity, and locus of control). Of the career development inventories, none have been specifically created to measure the career development of college student-athletes. Since previous literature illustrates that college student-athletes have different lifestyles than other college students (Blann, 1985; Sowa et al., 1983; Wittmer, 1981), studentathletes career development should not be measured by instruments that are normalized by other populations. 
To understand the complexity of career attitudes, beliefs, and interests of college studentathletes, Sandstedt, Cox, Martens, Ward, Webber and Ivey (2004) created the Student-Athlete Career Situation Inventory (SACSI). This 30-item inventory was based on previous scales and literature on student-athletes and career development. The SACSI measured the factors career development self-efficacy (6 items), career versus sport identity (9 items), locus of control (4 items), barriers to career development (6 items), and sport to work relationship (5 items). Responses for each item of the SACSI are anchored from (1) strongly disagree to (5) strongly agree, with (3) as neutral to capture any ambivalence the student-athlete may have been facing. High scores (including items that were reverse-coded and changed for scoring) indicated a high degree of career development. Internal consistency reliability for the factors career development self-efficacy, career versus sport identity, locus of control, barriers to career development, and sport to work relationship were $.78, .80, .70, .72$, and .73 , respectively, and the total scale was .83. To determine the criterion validity of the SACSI, two scales, "Experience" and "Perceived gains," were created. A sample item from the "Experience" scale included, "Talked to a student, instructor or coach about academic majors and careers that they lead to" (p. 85). Anchors for this scale were never, almost never, occasionally, often, or very often. A sample item from the "Gains" scale was, "Gained knowledge and skills applicable to a specific job or type of work" (p. 85). Anchors for this scale were not at all, somewhat, greatly, or definitely. Two hundred and four Division I college student-athletes (138 male and 66 females) completed the SACSI, the "Experiences" scale, and the "Gains" scale. Results from regression analyses for the variable "Experiences" indicated significant regression coefficients for the factors self-efficacy, career versus sport identity and locus of control $\left(R^{2}=.17, \mathrm{p}<.01\right)$. The factor locus of control had an inverse relationship with the variable "Experiences". For the variable "Gains", the factors self- 
efficacy and career verses sport identity displayed significant regression coefficients $\left(R^{2}=.28, p\right.$ $<.01)$

A later study from Cox, Sadberry, McGuire, and McBride (2009) found the factor structure for the SACSI (Sandstedt et al., 2004) to be different for male and female athletes. Data were collected over a 5-year period from 627 college student-athletes (326 males and 301 females) from a Division I university. Results from exploratory factor analysis of the 30-item SACSI (Sandstedt et al., 2004) lead to the creation of a 25-item (five-factor) SACSI-Revised for Males (SACSI-RM) and a 23-item (four-factor) SACSI-Revised for Females (SACSI-RF). Items were retained from the original SACSI (Sandstedt et al., 2004) if thy loaded at .45 or greater for a factor. Retained items needed to also have a factor loading of at least .15 greater than its loading on any other factor. If an item loaded on more than one factor, it was deleted. Items for both the SASCI-RM and the SACSI-RF were scored from (1) strongly disagree to (5) strongly agree. The five factors for the SACSI-RM were 1) career confidence (6 items), 2) low career interest (5 items), 3) academic/career important (4 items), 4) sport facilitates (5 items), and 5) Barriers (5 items). High scores are desirable on the positive factors 1, 3, and 4 (i.e. career confidence, academic/career important, and sports facilitates). Low scores are desired on the negative factors 2 and 5 (i.e. low career interest and barriers). Acceptable internal consistency was found for each factor (i.e. .79, .77, .70, .74, and .73). The four factors for the SACSI-RF were 1) Sport identity (8 items), 2) career confidence (5 items), 3) barriers (5 items), and 4) sport facilitates (5 items). High scores were desirable on the positive factors 2 and 4 (i.e. career confidence and sport facilitates). Low scores are desired on the negative factors 1 and 3 (i.e. sport identity and barriers). Internal consistency for the four factors were $.79, .82, .82$, and .76.

\section{College Student-Athletes Career Maturity Research}


Several researchers have studied the career maturity of college student-athletes. The inventories that were discussed in the previous section were the primary instruments used to gather data on college student-athletes. The following section will include the findings from studies pertaining to the career development of college student-athletes.

Students verses student-athletes. Several researchers have agreed that student-athletes differ from their non-athlete student counterparts with respect to career development (Blann, 1985; Kennedy et al., 1987, Wittmer et al., 1981). When compared to the CDI sample percentiles, male student athletes reported to be in the bottom 25\% (Smallman and Sowa, 1996). Murphy and colleagues also compared athletes to the percentile norms of the CMI and athletes scored in the $27^{\text {th }}$ percentile. Martens and Cox (2000) found significant career development differences between athletes and non-athletes. Non-athletes reporting higher MVS (Holland et al., 1980) scores than student-athletes, indicating a clear sense of vocational identity. Although significant, Martens and Cox (2000) were surprised that the differences between athletes and non-athletes were not greater. Since the MVS is based on one's vocational identity (i.e. individual clear and stable understanding of career goals and interests) these researchers explained that if athletes are convinced that they will play a professional sport they may have a high vocational identity. The previous findings indicate that student-athletes may not be as career prepared when compared to the career development norms or their student counterparts.

Expectation of a professional athletic career. Some student-athletes may have career aspirations to compete at the professional level. Blann's (1985) finding indicated that $28 \%$ of Division I male athletes planned to play professionally, while only $10 \%$ of the Division III male athletes believed this was a possibility. Kennedy and colleagues (1987) concluded that $48 \%$ of their student-athlete sample $(n=122)$ expected to play at the professional level. They further 
indicated that race may have an influence on an athlete's expectation to play professionally since a greater percentage of black athletes (66\%) indicated expectations to play professionally than white athletes (39\%). However, no further reasoning for these expectations were provided.

Smallman and colleagues (1996) revealed that of the Division I male student-athletes they sampled $(n=125), 34 \%$ expected to play at the professional level. Of these student-athletes who expected to play professionally, $57 \%$ believed that they had an average to excellent chance to play professionally, $19 \%$ did not know how good their chances were to play professionally, and $24 \%$ thought their chances to play professionally were poor. No further conclusions were made regarding this group. Brown, Glastetter-Fender, and Shelton (2000) revealed that out of 189 Division I student-athletes, $19 \%$ of participants expected to compete at the professional level, $39 \%$ had no expectation, leaving the remaining $42 \%$ to be uncertain of professional athletic careers. Nineteen percent of participants from Brown and Hartley's (1998) study selected professional athlete for their future occupational preference. These participants scored significantly lower on the CDI variables of decision making (DM), world of work information (WW) and knowledge of preferred occupational group (PO) when compared to participants who selected other vocations. These findings could lead one to believe that those who have a vested interest of becoming a professional athlete may not make the best career decisions, are not tuned into the working world, and have no knowledge of what they might do if a professional athletic career did not happen. Previous research indicates that a high percentage of college students have professional ambitions even though less than $2 \%$ of college student-athletes have the opportunity to pursue a professional athletic career.

Type of sport played. When investigating career development and type of sport played, conflicting results were found. Kennedy and Dimick (1987) found that male student-athletes 
from revenue sports had significantly lower levels of career maturity than male students.

Murphy, Petitpas, and Brewer (1996) found that revenue sport athletes reported having less career maturity than non-revenue athletes. However, other researchers have found type of sport played to have no significant effect on career development (Smallman \& Sowa, 1996; Martens \& Cox, 2000). Most recently, a study with 110 student-athlete participants from two Jamaican universities indicated that type of sport played had an effect of student-athletes' career situation (Samms, Kungu, Boolani, \& Johnson-Wisdom, 2012). These finding indicate that the type of sport played may or may not have an effect on career development.

Athletic identity. Researchers have found conflicting evidence when comparing career maturity and athletic identity. Murphy, Petitpas, and Brewer (1996) concluded that athletes with higher athletic identity displayed less career maturity. Furthermore, revenue sport athletes had greater athletic identity scores than non-revenue athletes. Brown and colleagues (1998) believed that student-athletes with a higher athletic identity would have lower career maturity scores. However, no significant results were found to confirm this hypothesis. Kornspan and Etzel (2001) later concluded that athletic identity was not a predictor of career maturity.

Identity foreclosure. When entering college, some students may commit to a career path with limited information and exploration, leaving them with a foreclosed identity (Marcia, 1966; Medalie, 1981). The same is possible for the college student-athlete. Student-athletes may be set on becoming a professional athlete, lawyer, doctor, without knowing what they may have to do to get there. Murphy, Petitpas, and Brewer (1996) concluded that identity foreclosure was inversely related to career maturity, meaning athletes with a foreclosed identity displayed less career maturity. Brown, Glastetter-Fender, and Shelton (2000) found identity foreclosure to be inversely related to career decision making self-efficacy (CDSE) scores. The student athletes 
who were less foreclosed had greater confidence in their ability to make career decisions. These results confirm that identity foreclosure may have an influence on career development.

Career decision self-efficacy. Decision making is a task that will occur on several occasions during the career development process. Career decision making self-efficacy is defined as having the confidence in one's ability to make career decisions (Taylor et al., 1987). Kornspan and colleagues (2001) found career decision self-efficacy to be the third most influential predictor of career maturity, accounting for $4 \%$ of the variance. College studentathletes are limited to participating in a maximum of 20 hours per week of "countable athletic related activities" (17.1.6.1, NCAA, 2012b). However, athletes can exceed the 20-hour rule if the athletic event is considered "voluntary" (17.02.13, NCAA, 2012b). Brown, GlastetterFender, and Shelton (2000) found that hours involved in sport participation was inversely related to CDMSE scores. Those athletes that dedicated more hours to their sport displayed less career decision self-efficacy. Although it can be assumed that student-athletes who invest more time in their sport may have a higher level of athletic identity, Brown and colleagues did not find a significant relationship between athletic identity and career decision self-efficacy. Nonetheless, self-efficacy in career decision making and hours dedicated to sport do appear to have an influence on the career development process.

Locus of control. Student-athletes' locus of control has an influence on their career development. Brown and colleagues (2000) found career locus of control to be inversely related to career decision self-efficacy. Student athletes who possessed an internal locus of control were found to have higher career decision self-efficacy scores. Kornspan and colleagues (2001) concluded that locus of control was the most influential predictor of career maturity. Having the belief that one's actions can determine (i.e. internal) or not determine (i.e. external) future 
outcomes is locus of control. Similar to self-efficacy theory (Bandura, 1977), those with an internal locus of control believe they have control over their futures and may put more effort into their career preparation (Trice et al., 1989).

Gender, race, level of competition. As for the relationship between gender and career development, Kornspan and colleagues (2001) determined that gender was the second most influential predictor of career maturity. Female student-athletes displayed higher levels of career maturity than male student-athletes (Murphy et al., 1996). Conflicting results were found regarding the variables: level of competition (e.g. Division I, Division II, and Division III) and race on career development (Blann, 1985; Brown et al., 1998; Kennedy et al., 1987; Smallman et al., 1996). Blann (1985) found that student-athletes from a Division III university reported having more developed career plans when compared to Division I student-athletes, however, Brown and colleagues (1998) did not find any significant results with career maturity and level of competition. While Kennedy and colleagues (1987) did not find any significant difference between black and white athletes attending a midwestern university, Smallman and Sowa (1996) found within a sample of student-athletes from a Division I southeastern university that white student-athletes had a greater awareness of their preferred occupations when compared to black student-athletes. Previous findings provide evidence that certain subgroups of student-athletes may be at more career development risk and these variables should be explored further.

\section{Career Development Programs for Student-Athletes}

This section will provide more detail about programs that have been developed to assist student-athletes in their career development. One of the first publically reported career development programs was at the University of Florida. This program, an exit seminar for graduating student-athletes, was created after administrators realized that some student-athletes 
expressed concerns about their futures following graduation (Wittmer et al., 1981). It is important to note that these seminars were created following a course designed to promote "growth and development of student-athletes" (p. 54). Career interests and planning were also included as part of this course.

With the hope of stimulating career preparation, other career development programs have been designed specifically with student-athletes in mind. Some of these programs have taken the form of academic courses that are taken for credit (Stankovich, Meeker, \& Henderson, 2001; Wooten \& Hinkle, 1994), while others plan career related events and seminars for studentathletes throughout the year (Lenz \& Shy, 2003, Naylor, 1983). The general premise for these programs is to provide student-athletes with the tools and resources to learn about themselves, the world of work, and build skills to pursue their career and work interests (Lenz et al., 2003; Naylor, 1983; Stankovich et al., 2001; Wooten et al., 1994). For example, an evaluation of the Positive Transitions program revealed increases in career maturity, confidence in decisionmaking skills, and a readiness to retire from sport (Meeker \& Stankovich, 1999). While these programs are of importance, for them to be successful, researchers have stressed the importance of having the support of the athletic department, coaches, athletes, parents and alumni (Lenz et al., 2003; Meeker \& Stankovich, 1999; Naylor, 1983).

\section{Career Counseling}

Several researchers have provided definitions and frameworks for career counseling (Brown, 2003; Drummond \& Ryan, 1995; Swanson, 1995). To summarize, career counseling is a process intended to facilitate self-exploration, career development, career decision making, career planning and gaining occupational knowledge, by means of assessment, providing occupational information and personal counseling (Brown, 2003). Brown (1991) also suggested 
that a stereotype existed of career counseling being a simple process that helped people learn about themselves and occupations to help them make "good" decisions. Manuele-Adkins (1992) classifies career counseling as a short-term intervention that some counselors have considered to be a lower standard of personal counseling. Furthermore, there has been debate regarding the differences, if any, between career counseling and psychotherapy (Bluestein \& Spengler, 1995; Hackett, 1993; Manuele-Adkins, 1992; Swanson, 1995), however, Bluestein and colleagues (1995) concluded that career counseling and psychotherapy are not identical, but they are related. As career counseling is a helping profession, the following section will review attitudes toward seeking professional help and career counseling.

\section{Attitudes Toward Seeking Psychological Help and Career Counseling}

Individuals can seek and use counseling services for a variety of reasons (Fischer \& Turner; 1970). While universities provide psychological services and career counseling to their students, these services may be underutilized. Fouad, Guillen, Harris-Hodge, Henry, Novakovic, and Kanatamneni (2006) found that within a sample of 694 students attending a large, urban, Midwestern university, $42 \%$ of students knew counseling services were available and $51 \%$ of students were aware that individual career counseling was available to them, but only $6.8 \%$ and $6.1 \%$ of students sampled indicated use of these services, respectively. These researchers have also identified several reasons why students would not use career counseling services (e.g. uncertain about career counseling process, thought it would not be helpful, or turned to others for guidance) even though participants indicated they would be comfortable with career counseling.

Attitudes toward seeking psychological help. Fischer and Turner (1970) believed that one's attitude, either positive or negative, would influence their decision to seek professional help for psychological difficulties. With the assistance of mental health professionals at varying 
levels a 31-item inventory, Attitudes Toward Seeking Professional Psychological Help Scale (ATSPPHS), was created to assess attitudes toward seeking professional help for psychological problems. A sample item included, "If I believed I was having a mental breakdown, my first inclination would be to get professional attention.” (p. 82). This inventory was given to high school students $(n=78)$, nursing students $(n=19)$, and college students in a summer program and participants were asked to give their opinion of each item using 0 to 3 scale. Only two items correlated poorly leaving, the final version of the inventory to have 29 -items, 11 which were positively stated, and 18 that were negative stated (reversed score for analysis). Scores ranged from 0 to 87 with high scores indicating a positive attitude toward seeking professional help. Internal reliability for this sample was .86 . The reliability estimate was .83 for a sample of 406 participants, but specific information about this sample was not described in the study. Testretest reliability was established over different time intervals ( 5 days, two weeks, four weeks, six weeks, and two months) with scores ranging from .73 (six week group) to .89 (two-week group).

A shortened version of the ATSPPHS was created and consisted of 10 items from the original (Fischer \& Farina, 1995). Three hundred and eighty-nine undergraduate students complete the new inventory which was scored from 0 to 3 or 3 to 0 depending on the negative or positive orientation of the item. Scores ranged from 0 to 30 , with high score indicating a positive attitude toward seeking help. Internal consistency was .84, which was similar to Fischer and colleagues (1970) (i.e. .83 and .86). Test-retest reliability was established with another sample of undergraduate students $(N=62)$ one month apart. Participants initially completed the new 10 item inventory and later completed the 10-item inventory and the previous 29-item ATSPPHS (Fischer et al., 1970). After the one month interval the reliability estimate was .80 and the correlation between the new 10-item inventory and old 29-item inventory was .87. 
Fischer and colleagues (1995) found a significant correlation with gender and attitude toward seeking professional help, with women scoring higher than men, suggesting that women are more favorable about seeking help when compared to men. When compared to the sample from Fischer and colleagues in 1970, the participants in their 1995 study had less favorable attitudes toward seeking psychological help. Watson (2005) compared college student-athletes $(n=135)$ and non-athletes $(n=132)$ and found that student-athletes had less positive attitudes toward seeking professional help.

In an effort to promote the benefits of using psychological services, other researchers have looked at variables that influence attitudes toward seeking psychological help. In a two part study, Vogel and Wester (2003) also provided a rational for why students do not seek counseling. With a sample of 209 college students, these researchers found that self-disclosing distressing information, the client's perceived value in disclosing information (i.e. anticipated utility), the client's perceived risk in disclosing information (i.e. anticipated risks), and general emotional disclosure (i.e. depression, happiness, jealousy, anxiety, anger, calmness, apathy, and fear) were predictors of attitudes toward seeking help. In their second study with a sample of 268 undergraduate students, Vogel and colleagues (2003) found that anticipated utility, anticipated risks, disclosure of distressing information, one's propensity to hide distressing information from others (i.e. self-concealment), and previous use of therapy contributed to attitudes toward seeking help. Additionally, Watson (2005) found that expectations about counseling influenced an individual's attitude toward seeking help. Rather than only looking at the individual, Vogel, Wade, and Hacker (2007) investigated how individual attitudes could be influenced by others. These researchers found that a perceived stigma from the general public 
about seeking professional psychological help forces an individual to internalize this stigma which, in turn, influences their decision to seek assistance.

Attitudes toward career counseling. Through previous research it has been determined that there are several variables that influence one's attitude to seek professional psychological help (Vogel et al., 2003; Vogel et al., 2007). While attention has been given to attitudes toward seeking psychological assistance, it was not until 1999 that Rochlen, Mohr, and Hargrove investigated attitudes toward career counseling specifically. It was believed that attitudes consisted of cognitive, affective, and behavioral components. So, a preliminary pool of 27-items (minimum of seven for each component) was created by two counseling psychologist and eight graduate student whom had career counseling training. These items were pilot tested on 68 undergraduate students. Following feedback from the participants, graduate students, and counseling psychologists, items that were unclear or confusing were deleted, and 15 additional items were created, yielding a pool of 36 items.

The 36-item measure was administered to 467 undergraduate students in three different settings (i.e. introductory psychology course at a large Mid-Atlantic university, incoming firstyear students in a summer transitional course at the same university, and students enrolled in a community college sociology course). The majority of participants were women $(n=270)$, were between the age $18-20$ years (73\%), and were white (56\%). A one-way analysis of variance showed no mean difference between the three settings, so a factor analysis was conducted and produced a two-factor solution that accounted for $80 \%$ of the variance. Items loading at least .40 on only one factor were used to construct two initial subscales with 15 and 14 items. Rochlen and colleagues (1999) made the instrument shorter and easier to administer by eliminating items with the least variability and the smallest discrepancy in loading between factors. This process 
produced a 16-item scale, known as the Attitudes Towards Career Counseling Scale (ATCCS), and consists of two subscales; Value (8-items) and Stigma (8-items).

The Value subscale measures the perceived value and usefulness of career counseling. A sample item from the Values subscale reads, "If I was in a career transition, I would value the opportunity to see a career counselor." Responses from each item are anchored with (1) strongly disagree, (2) disagree, (3) mildly disagree, (4) mildly agree, (5) agree, and (6) strongly agree. Higher scores indicate a positive perception of career counseling. The Stigma subscale measures shame, stigma, and negative feelings associated with career counseling. A sample item of the Stigma subscale reads, "I would be too embarrassed to ever schedule an appointment with a career counselor." Responses have the same anchors as the Values subscale, but high scores indicate a greater amount of stigma toward career counseling. Although the ATCCS (Rochlen et al., 1999) used a 4-point scale, a 6-point scale with the same anchors stems has been used in other studies to increase the variance in scores (Rochlen \& O'Brien, 2002; Rochlen, Blazina, \& Rahunathan, 2002).

Validity of the ATCCS. Rochlen and colleagues (1999) dedicated two parts of their five part study to the construct validity of the ATCCS. The construct validity for these two studies will be discussed in the following sections and will be referred to as Study 1 and Study 2.

Study 1 . In the first study, the construct validity was determined by comparing the ATCCS with the ATTPPHS (Fischer et al., 1995), the Adult Attachment Scale (AAS, Collins \& Read, 1990 as cited in Rochlen et al., 1999), the General Decision-Making Style (GDMS Scale; Scott \& Bruce, 1995 as cited in Rochlen et al., 1999), and the Social Desirability Scale (SDS; Crowne \& Marlowe, 1960 as cited in Rochlen et al., 1999). The ATSPPHS measures general attitudes toward seeking professional help for psychological concerns. The AAS measures the 
extent to which individuals trust others and depend on their availability when needed. The GDMS assesses five decision-making styles; 1) Rational, 2) Intuitive, 3) Dependent, 4) Spontaneous, and 5) Avoidant. The SDS measures the likelihood that an individual responds to an answer in a manner that appears to be socially acceptable. A demographic questionnaire was also created to determine participants' age, gender, ethnicity, and to assess whether they have selected a major, a career, if they have been in career counseling, and their likelihood of seeking career counseling.

The aforementioned scales and questionnaires were administered to 125 student participants (74 women, 51 men) from an introductory undergraduate psychology course. It was hypothesize that the Value subscale would be positively correlated with the ATSPPHS, and that the Stigma subscale would have an inverse relationship with the ATSPPHS. The results of this study indicated a moderate correlation between the ATSPPHS and both the Value $(r=.34, p$ $<.001)$ and Stigma $(r=-.35, p<.001)$ subscales. These results lead one to believe that the ATCCS measures attitudes toward career counseling.

In terms of decision-making styles, it was hypothesized that individuals who expressed dependent decision making styles would value career counseling and would be less likely to have a stigma toward such services. This hypothesis was confirmed as higher Values scores were related to greater use of dependent decision-making styles $(r=.33, p<.001)$. So, individuals who are comfortable with being dependent on others valued career counseling. It was also hypothesized that individuals who possessed spontaneous and avoidant decision making styles would be more likely to place less value on career counseling. This hypothesis was partly confirmed with those who expressed spontaneous decision-making styles placing less value on 
career counseling $(r=-.26, p<.025)$. There was no relationship found with the avoidant decision-making and the Values subscale.

Concerning the demographic questionnaire, Rochlen and colleagues (1999) also believed that male participants would report less value and higher stigma toward career counseling when compared to women. The results indicated no relationship between gender and Values scores ( $r$ $=-.15, n s)$, however, men reported having higher Stigma scores than women $(r=.35, p<.001)$. Additionally, the researchers believed participants with previous career counseling experience would report less stigma toward career counseling and those with a willingness to seek these services would have a high value scores and low stigma scores. Results revealed that participants who had previous career counseling experiences had less stigma $(r=-.25, p<.025)$, and those with a higher likelihood to seek career counseling had high Value scores $(r=.46, p<$ $.001)$ and low Stigma scores $(r=-.45, p<.001)$.

To address the discriminant validity of the ATCCS, it was hypothesize that the ATCCS subscales would have no relationship with the measure of social desirability, the selection of a major or career, and previous experience with career counseling should not be correlated with the value of the service. No relationship emerged between either of these variables.

Study 2. Further evidence supporting the construct validity of the ATCCS was obtained from collecting data from 69 students from an introductory psychology course (Rochlen et al., 1999). These participants completed the demographic questionnaire detailed in Study 1, the ATSPPHS (Fischer et al., 1995), the Intentions of Seeking Counseling Inventory (ISCI; Cash, Begley, McCown, \& Weise, 1975 as cited in Rochlen et al., 1999), the Psychotherapy and Stigma Scale (PASS; Judge \& Gelso, 1998 as cited in Rochlen et al., 1999), Commitment to Career Choices Scale (CCCS; Bluestein, Ellis, \& Devenis, 1989 as cited in Rochlen et al., 1999). 
The ISCI measures college students' likelihood of seeking help for common issues that are brought to counseling. The PASS has three subscales that measure an individual's beliefs of the secrecy of therapy, societal perception of therapy, and perceptions of who belongs in therapy. The $C C C S$ measures an individual's vocational exploration and commitment toward a career path, and the tendency to foreclose on a career path.

The researchers hypothesized that similar results from Study 1 would be found between the demographic variables, the ATSPPHS, and the ATCCS. Most of these findings were replicated in Study 2, but only significant results will be reported. Therefore, the Values subscale was positively correlated with the ATSPPHS, and the Stigma subscale had an inverse relationship with the ATSPPHS. Participants who indicated a higher likelihood to seek career counseling had high Value scores and low Stigma scores. Men reported having higher Stigma scores than women, and no relationship was found between gender and Value.

It was also believed that individuals who score high on Stigma subscale of the ATCCS would also have high scores on each of the subscales (i.e. Secrecy of Therapy, Societal Stigmatization, and Who Belongs in Therapy) of the PASS. The subscales Secrecy $(r=.47, p<$ $.001)$ and Who Belongs in Therapy $(r=.37, p<.025)$ were correlated with Stigma subscale of the ATCCS. It was further hypothesized that the Value subscale would have a positive moderate relationship with items from the $I S C I$, and this hypothesis was confirmed $(r=.24, p<.05)$. Discriminant validity for the ATCCS was further confirmed as there was no relationship found with the items of the CCCS and societal stigmatization.

Reliability of the ATCCS. During the development of the ATCCS, Rochlen and associates (1999) completed a five part study investigating attitudes toward career counseling. Their results revealed internal consistency estimates for the Value subscale that ranged from .85 
to .90 , and from .80 to .83 on the Stigma subscale (Rochlen et al., 1999). Three other studies have used the ATCCS. In a study with 300 male psychology students, internal consistencies estimates for the ATCCS were .85 and .79 for the Value and Stigma subscales, respectively (Rochlen \& O’Brien, 2002). In another study, the ATCCS was administered to 123 male undergraduate students in the education psychology and marking departments prior to and following the review a brochure about career counseling. Pre-brochure internal consistency estimates were .85 and .79 for the Value and Stigma subscales, respectively, and post-brochure estimates were .92 and .82 (Rochlen, Blazina, Raghunathan, 2002). Ludwikoski, Vogel, and Armstrong (2009) only used the Value subscale with a sample of 509 students (238 men, 268 women) from and intro psychology class at a large Midwestern university and internal consistency estimates were .89 .

Summary of findings related to the ATCCS. When comparing gender and attitudes toward career counseling, men reported a higher degree of stigma than women (Rochlen et al., 1999; Ludwikoski, Vogel, \& Armstrong, 2009), and value toward career counseling illustrated varying conclusions (Rochlen et al., 1999; Ludwikoski, et al., 2009). While Ludwikoski and colleagues (2009) reported that men valued career counseling more than women, Rochlen and colleagues (1999) did not find a relationship between gender and values toward career counseling. Rochlen and O'Brien (2002) also concluded that men who were more restrictive in expressing emotions and were uncomfortable with the closeness of other men tended to have higher stigmas toward career counseling.

Rochlen and colleagues (1999) concluded that valuing and having a low stigma toward career counseling increased one's likelihood to seek career counseling. Having previous experience with career counseling also lowered the stigma toward career counseling. Similar to 
Vogel and colleagues (2007), Ludwikoski and colleagues (2009) concluded that public stigma and personal stigma predicted self-stigma, which in turn predicted one's attitude to seek career counseling.

\section{Summary}

Student-athletes are not as prepared for non-athletic careers as non-athlete students (Linnemeyer \& Brown, 2010; Martens \& Cox, 2000). Some researchers have argued that the time commitment to their sport (Carodine et al., 2001; NCAA, 2011), going to college for reasons other than academics (Letawsky et al., 2003), or having had their lives planned for them and expecting this same process to continue (Underwood, 1980) have an influence on their career development. While few student-athletes have the opportunity to become professional athletes, the majority will pursue other career paths following graduation or completion of their athletic eligibility. To help student-athletes prepare for careers after college, career preparation programs and courses have been specifically designed for college student-athletes (Lenz et al., 2003; Naylor, 1983; Stankovich et al., 2001; Wooten et al., 1994). Even though these programs may be provided to college student-athletes, these programs cannot benefit student-athletes if they are not utilized. The same can be said for career counseling services provided by universities. But why wouldn't student-athletes utilize these services? Watson (2005) has suggested that student-athletes attitudes toward services can be a contributor to the underutilization of counseling and support services. In turn, other researchers have suggested that attitudes toward career counseling can be affected by stigmas or the amount of value that college students place on career counseling (Rochlen et al., 1999; Ludwikoski, et al., 2009). In the case of college student-athletes, some attention has been given to the study of their career situation and attitudes toward career counseling independently, but there is no research on the 
relationship of these variables. While student-athletes and non-athlete students have been compared on various career and graduation variables, there is no research comparing the attitudes toward career counseling for these two groups. Therefore, this study will focus on 1) the career situation of male and female Division I college student-athletes, 2) student-athlete and non-athlete student attitudes toward career counseling, and 3) finding which variables, if any, are predictors of student-athletes attitudes toward career counseling. 


\section{References}

Bandura, A. (1977). Self-efficacy: Toward a unifying theory of behavioral change. Psychological Review, 84, 191-215

Betz, N. E., Klein, Klein, K. L., \& Taylor, K. M. (1996). Evaluation of a short form of the Career decision-making self-efficacy scale. Journal of Career Assessment, 4(1), 47-57.

Brewer, B.W., \& Cornelius, A.E. (2001). Norms and factorial Invariance of the athletic identity measurement scale (AIMS). The Academic Athletic Journal, 15, 103-113.

Brewer, B.W., Van Raalte, J.L., \& Linder, D.E., (1993). Athletic Identity: Hercules' muscles or achilles' heel? International Journal of Sport Psychology, 24, 237-254.

Brown, D. (2003). Career information, Career Counseling, and Career Development ( $8^{\text {th }}$ ed.) Boston, MA; Allyn and Bacon.

Brown, C., Glastetter-Fender, C., \& Shelton, M. (2000). Psychosocial Identity and Career Control in College Student-Athletes Journal of Vocational Behavior 56, Issue 1, 53-62.

Brown, C., \& Hartley, D.L. (1998). Athletic identity and career maturity of male college student athletes. International Journal of Sport Psychology 29(1), 17-26.

Busacca, L.A., \& Taber, B.J. (2002). The career maturity inventory-revised: A preliminary psychometric investigation. Journal of Career Assessment, 10(4), 441-455.

Carodine, K., Almond, K.F., \& Gratto, K. (2001). College student athlete success both in and out of the classroom. New Directions for Student-Services, 2001(93), 19-33.

Chickering, A.W. (1967). Institutional objectives and student development in college. The Journal of Objectives and Student Development. 3(3), 287-304.

Crites, J.O. (1961). A model for the measurement of vocational maturity. Journal or Counseling Psychology, 8(5), 255-259. 
Crites, J.O. (1976). A comprehensive model of career development in early adulthood. Journal of Vocational Behavior, 9, 105-118.

Crites, J. O., \& Savickas, M. L. (1996). Revision of the Career Maturity Inventory. Journal of Career Assessment, 4(2), 131-138.

Drummond, R.J., \& Ryan, C.W. (1995). Career counseling: A developmental approach. Englewood Cliffs, NJ: Merrill-Prentice Hill.

Fischer, E.H., \& Farina, A. (1995). Attitudes toward seeking professional psychological help: A shortened form and considerations for research. The Journal of College Student Development, 36(4), 368-373.

Fischer, E.H., \& Turner, J.L. (1970). Orientations to seeking professional help: Development and research utility of an attitude scale. Journal of Counseling and Clinical Psychology, 35(1), 79-90.

Fouad, N.A., Guillen, A., Harris-Hodge, E., Henry, C., Novakovic, A. Terry, S., \& Kanatamneni, N. (2006). Need, awareness and use of career services for college students. Journal of Career Assessment, 14(4), 407-420.

Hackett, G. (1993). Career counseling and psychotherapy: False dichotomies and recommended remedies. Journal of Career Assessment, 1, 105-107.

Hansen, J. C. (1974). Test review: J. O. Crites, Career Maturity Inventory. Journal of Counseling Psychology, 21(2), 168-172.

Holland, J.L., Gottfredson, D.C., \& Power, P.G. (1980). Some diagnostic scale for research in decision making and personality: Identity, information, and barriers. Journal of Personality, 39(6), 1191-1200. 
Kennedy, S. R., \& Dimick, K. M. (1987). Career maturity and professional sports expectations of college football and basketball players. Journal of College Student Personnel, 28(4), 293 297.

Knight Commission on Intercollegiate Athletics. (2001). A call to action: Reconnecting college sports and higher education.

Kornspan, A.S., \& Etzel, E.F. (2001). The relationship of demographic and psychological varisbles to career maturity of junior college student-athletes. Journal of College Student Development, 42(2), 122-132.

Lally, P., \& Kerr, G, (2005). The career planning, athletic identity, and student role identity of intercollegiate student athletes. Research Quarterly for Exercise and Sport, 76, 275-285.

Lenz, J.G., \& Shy, J.D. (2003). Career services and athletics: Collaborating to meet the needs of student-athletes. NACE Journal, 63(3), 36-41.

Letawsky, N.R., Schneider, R.G., Pedersen, P.M., \& Palmer, C.J. (2003). Factors influencing the college selection process of student-athletes: Are their factors similar to non-athletes. College Student Journal, 37(4), 604-610.

Linnemey, R.M., \& Brown, C. (2010). Career maturity and foreclosure in student athletes, fine arts students, and general college students. Journal of Career Development, 37(3), 616634.

Lucas, E.B., Gysbers, N.C., Buescher, K.L., \& Heppner, P.P. (1988). My vocational situation: Normative psychometric, and comparative data. Measurement and Evaluation in Counseling and Development, 20(4), 162-170.

Ludwikoski, W.M.A., Vogel, D., \& Armstrong, P.I. (2009). Attitudes toward career counseling: The role of public and self-stigma. Journal of Counseling Psychology, 56(3), 408-416. 
Luzzo, D.A. (1995). The relative contributions of self-efficacy and locus of control to the prediction of career maturity. Journal of College Student Development, 36 (1), 61-66.

Manuele-Adkins, C. (1992). Career counseling is personal counseling. Career Development Quarterly, 40(4). 313-323.

Marcia, J.E. (1966). Development and validation of ego-identity status. Journal of Personality and Social Psychology, 3(5), 551-558.

Medalie, J.M. (1981). The college years as a mini-life cycle: Development tasks and adaptive options. Journal of American College Health Association, (30)2, 75-79.

Martens, M.P., \& Cox, R.H. (2000). Career Development of College Varsity Athletes. Journal of College Student Development, 41(2), 172-179.

Meeker, D., \& Stankovich, C. (1999). Positive transitions programs prepares student-athletes after the cheering stops. Athletics Administration, 34-35.

Murphy, M., Petitpas, A.J., \& Brewer, B.W. (1996). Identity foreclosure, athletic identity, and career maturity in intercollegiate athletes. The Sport Psychologist, 10, 239-246.

National Collegiate Athletic Association. (Sept. 1, 2010). Academic Progress Rate. Retrieved October, 29, 2012, from http://www.ncaa.org/wps/wcm/connect/public/NCAA/Resources/Research/Academic+Pr ogress+Rate .

National Collegiate Athletic Association (NCAA, 2011). Examining the student-athlete experience through the NCAA GOALS and SCORES studies. NCAA Convention. January 13, 2011. San Antonio, TX.

National Collegiate Athletic Association (NCAA, 2012b). 2012 - 2013 NCAA Division I Manual. 
Naylor, N. (1983). Career planning for student athletes. AGB Reports, 25(6), 21-29.

Paskus, T.S. (2012). A summary and commentary on the quantitative results of current NCAA academic reforms. Journal of Intercollegiate Sport, 5, 41-53.

Pinkney, J.W., \& Tebbe, C. (2009). The college student-athlete experience and academics. In E. Etzel, Counseling and Psychological Services for College Student-Athletes (pp. 257-282). Morgantown, WV: Fitness Information Technology.

Rochlen, A.B., Mohr, J.J., \& Hargrove, B.K. (1999). Development of the attitudes towards career counseling scale. Journal of Counseling Psychology, 46(2), 196-206.

Rochlen, A.B., \& O'Brien, K. M. (2002b). The relation of male gender role conflict and attitudes toward career counseling to interest in and preferences for different career counseling styles. Psychology of Men \& Masculinity, 3(1), 9-21.

Rochlen, A.B., Blazina, C., \& Raghunathan, R. (2002). Gender role conflict, attitudes toward career counseling, career decision-making, and perceptions of career counseling advertising brochures. Psychology of Men \& Masculinity, 3(2), 127-137.

Sandstedt, S.D., Cox, R.H., Martens, M.P., Ward, D.G., Webber, S.N., \& Ivey, S. (2004). Development of the Student Athlete Career Situation Inventory. Journal of Career Development, 31, 79-93.

Samms, C.L., Kungu, K., Boolani, A.B., \& Johnson-Wisdom, D. (2012). Proceedings from Academy of Organizational Culture, Communication and Conflict 2012: Student-athlete career situation awareness: Jamaican case. New Orleans, LA.

Savickas, M.L., \& Hartung, P.J. (1996). The career development inventory in review: Psychometric and research findings. Journal of Career Assessment, 4(2), 171-188. 
Smallman, E., \& Sowa, C. J. (1996). Career maturity levels of male intercollegiate varsity athletes. Career Development Quarterly, 44(3), 270 -277.

Stankovich, C.E. (1998). The effectiveness of a career development intervention program designed to assist student athletes through the sport retirement transition. Unpublished Dissertation.

Stankovich, C.E., Meeker, D.J., \& Henderson, J.L. (2001). The positive transition model for sport retirement. Journal of College Counseling, 4, 81-84.

Super, D. (1957a). The Psychology of Careers: An introduction to vocational development. Harper and Row, publishers. New York and Evanston.

Super, D., Crites, J., Hummel, R., Moser, H., Overstreet, P., \& Warnath, C. (1957b). Vocational Development: A framework for research. Teachers College, Columbia University. American Book-Stratford Press, Inc., New York.

Super, D.E. (1973). The Career Development Inventory. British Journal of Guidance and Counseling, 1(2), 37-50.

Swanson, J.L. (1995). The process and outcome of career counseling. In W.B. Walsh \& S.H. Osipow (2nd ed.), Handbook of Vocational Psychology: Theory, research, and practice. (217- 258). Mahwah, NJ: Lawrence Erlbaum Associates.

Taylor, J., \& Ogilvie, B.C. (1994). A conceptual model of adaptation to retirement among athletes. Journal of Applied Sport Psychology, 6, 1-20.

Taylor, K.M., \& Betz, N.E. (1983). Applications of Self-efficacy theory to the understanding and treatment of career indecision. Journal of Vocational Behavior, 22, 63-81.

Underwood, J. (1980). The writing is on the wall. Sports Illustrated, 52(21), 36-71. 
Vogel, D.L., Wade, N.G., \& Hacker, A.H. (2007). Perceived public stigma and the willingness to seek counseling: The mediating roles of self-stigma and attitudes toward counseling. Journal of Counseling Psychology, 54(1), 40-50.

Vogel, D.L, \& Wester, S. R. (2003). To seek help or not to seek help: The risks of selfdisclosure. Journal of Counseling Psychology, 50(3), 351-361.

Watson, J.C. (2005). College student-athletes' attitudes toward help-seeking behavior and expectations of counseling services. Journal of College Student Development, 46(4), 442-449.

Watt, S.K., \& Moore III, J.L. (2001). Who are student athletes? New Directions for Student Services, 93, 7-18.

Winston, R.B., Mill, T.K., \& Prince, J.S. (1979). Assessing Student Development: A preliminary manual for the Student Development Task Inventory (Revised Second edition), Athens, GA: Student Development Associates.

Wittmer, J., Bostic, D., Phillips, T.D., \& Waters, W. (1981). The personal, academic, and career problems of college student athletes: Some possible answers. The Personnel and Guidance Journal, September, 52-55.

Wooten, H.R., \& Hinkle, J.S. (1994). Career life planning with college student-athletes. TCA Journal, 22, 35-39 